\title{
Nanowires: properties, applications and synthesis via porous anodic aluminium oxide template
}

\author{
JAYA SARKAR, GOBINDA GOPAL KHAN ${ }^{\dagger}$ and A BASUMALLICK* \\ Department of Metallurgy and Materials Engineering, ${ }^{\dagger}$ School of Materials Science and Engineering, \\ Bengal Engineering and Science University, Howrah 711 103, India
}

MS received 10 July 2006; revised 19 April 2007

\begin{abstract}
Quasi one-dimensional nanowires possess unique electrical, electronic, thermoelectrical, optical, magnetic and chemical properties, which are different from that of their parent counterpart. The physical properties of nanowires are influenced by the morphology of the nanowires, diameter dependent band gap, carrier density of states etc. Nanowires hold lot of promises for different applications. Basic electronic devices like junction diodes, transistors, FETs and logic gates can be fabricated by using semiconductor and superlattice nanowires. Thermoelectric cooling system can be fabricated by using metallic nanowires. Semiconductor nanowire junctions can be used for different opto-electronic applications. Moreover, periodic arrays of magnetic nanowires hold high potential for recording media application. Nanowires are also potential candidates for sensor and bio-medical applications.

In the present article, the physical and chemical properties of nanowires along with their probable applications in different fields have been reviewed in detail. The review also includes highlights of the synthesis of nanowires via porous anodic aluminium oxide template since the technique is simple, cost-effective and a low temperature technique.
\end{abstract}

Keywords. Nanowire; properties; quantum-confinement; AAO template; electro-deposition.

\section{Introduction}

Recently, nanowires and nanorods of metallic and semiconducting materials have drawn a lot of research interest because of their unique physical properties (Ratner and Ratner 2003; Way 2003), which are interesting from the view point of different device applications. Nanowires have two quantum-confined dimensions and one unconfined dimension. Therefore, the electrical conduction behaviour of nanowires is different from that of their bulk counterpart. In nanowires, electronic conduction takes place both by bulk conduction and through tunneling mechanism. However, due to their high density of electronic state, diameter-dependent band gap, enhanced surface scattering of electrons and phonons, increased excitation binding energy, high surface to volume ratio and large aspect ratio, nanowires of metals and semiconductor exhibit unique electrical, magnetic, optical, thermoelectric and chemical properties compared to their bulk parent counterparts. The interesting properties of nanowires hold lot of promises for applications in the fields of electronics, optics, magnetic medium, thermoelectronic, sensor devices etc (Tonucci et al 1992; Whitney et al 1993). In view of the

*Author for correspondence

(abasumallick@metal.becs.ac.in, abm@matsc.becs.ac.in) interest and immense importance that has been attached to the different properties and applications of nanowires, herein we present a review on the current state of nanowire research. The review aims at highlighting the properties of nanowires and their probable applications in different fields. In addition to this the review also covers in detail the synthesis of nanowires by using porous alumina oxide template.

\subsection{Magnetic properties}

Magnetic nanowire arrays consisting of isolated needle-like magnetic nanowires have recently aroused considerable interest from the viewpoint of perpendicular magnetic recording. The nanowires that are introduced into the pores of alumina template by electrodeposition are potentially capable of producing bit densities in excess of $100 \mathrm{Gbit} \mathrm{in}^{-2}$. When the magnetic field is applied parallel to the long axis of the magnetic nanowire, it exhibits a coercive field, which is inversely proportional to the pore diameter (Chien 1991; Thurn-Albrecht et al 2000). It has also been reported that the squareness of the hysteresis loop can be increased from $30 \%$ up to nearly $100 \%$ by decreasing the wire diameter, $D_{\mathrm{p}}$.

Figures 1(a) and (b) show the variation of squareness of the hysteresis loop as a function of the applied magnetic 
field $(H)$ parallel and perpendicular to the wire axes for different nanowire diameters. A gradual increase of coercivity is observed with increasing aspect ratio (length $(l) /$ diameter $(d)$ ), but little change is observed when $l / d>10$ (Skomsk et al 2000). Moreover, now it has been established that depending on the geometry, different sites on the surface will differ in local coordination number, which may lead to the variation of moment with local environment (Liu et al 1989). Here, it is also important to note that changes in the diameter of the nanowires may influence the surface energies of the different crystallographic planes. It has been reported that in the case of $b c c$ $\alpha$-Fe, the order of surface free energy $(\gamma)$ for $(110),(100)$ and (111) planes is $\gamma_{110}<\gamma_{100}<\gamma_{111}$, where the values of $\gamma_{110}$ and $\gamma_{100}$ are close to each other. However, it has been found that as the diameter of the nanowire increases, the differences in the surface free energy between the crystallographic planes become more significant. Therefore, when nanowires are processed at low temperatures, growth of
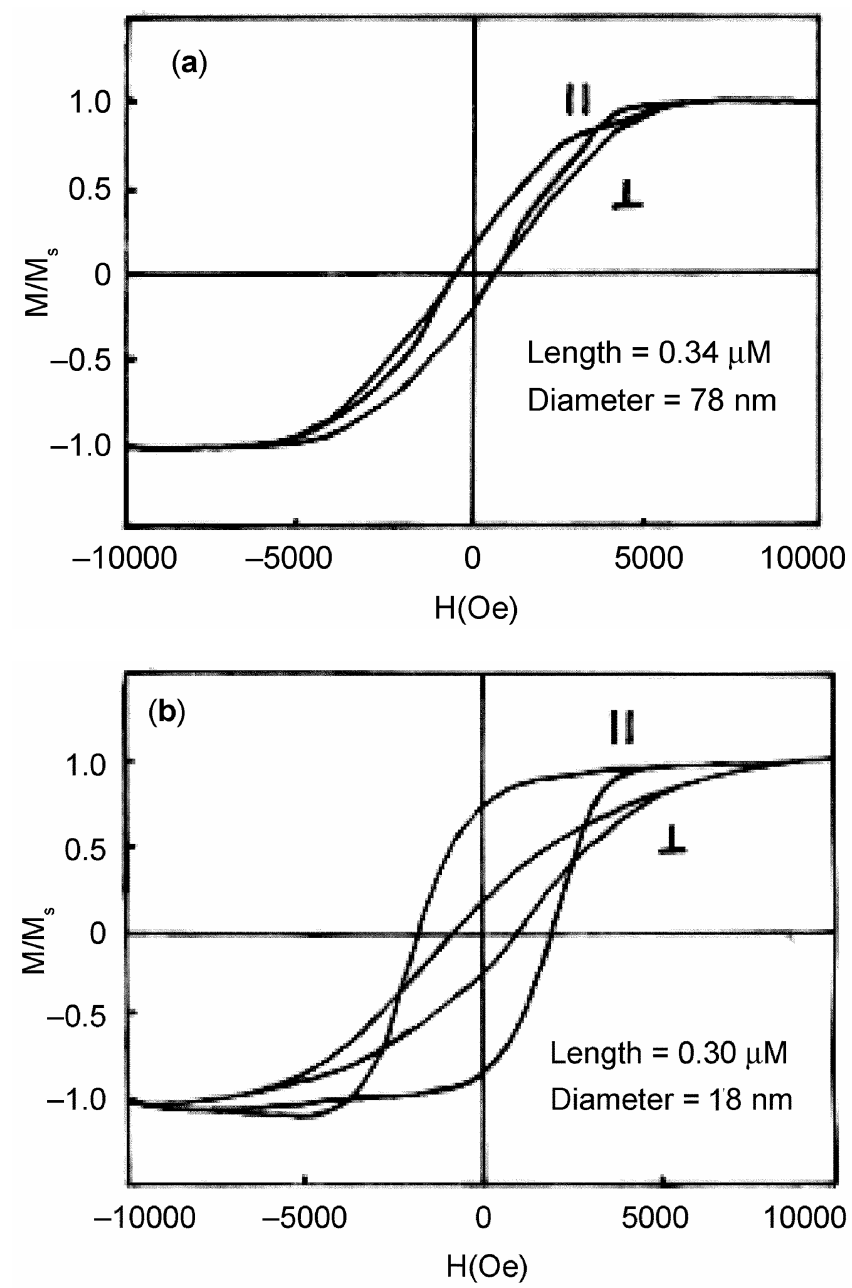

Figure 1. The variation of squareness of hysteresis loops of Co nanowire arrays with applied magnetic field $(H)$ parallel $(\|)$ and perpendicular $(\perp)$ to the wire axes: (a) nanowire diameter, $78 \mathrm{~nm}$ and (b) nanowire diameter, $18 \mathrm{~nm}$ (Beck et al 2005).
(110) and (100) planes are nearly equal giving rise to octagonal cross section of the nanowires. At higher temperatures, growth of (110) plane predominates and square shaped nanowires are formed (Aldén et al 1994; Vitos et al 1998; Spencer et al 2002). This change in morphology is expected to cause a change in the magnetization characteristic of the material. Therefore, it is apparent that one can tune the magnetic properties of the nanowires by simply changing their diameter, which will change coercivity, magnetization, remanance and squareness of the hysteresis loop.

It has been found that the total magnetic anisotropy of these nanowires is significantly influenced by the magnetic
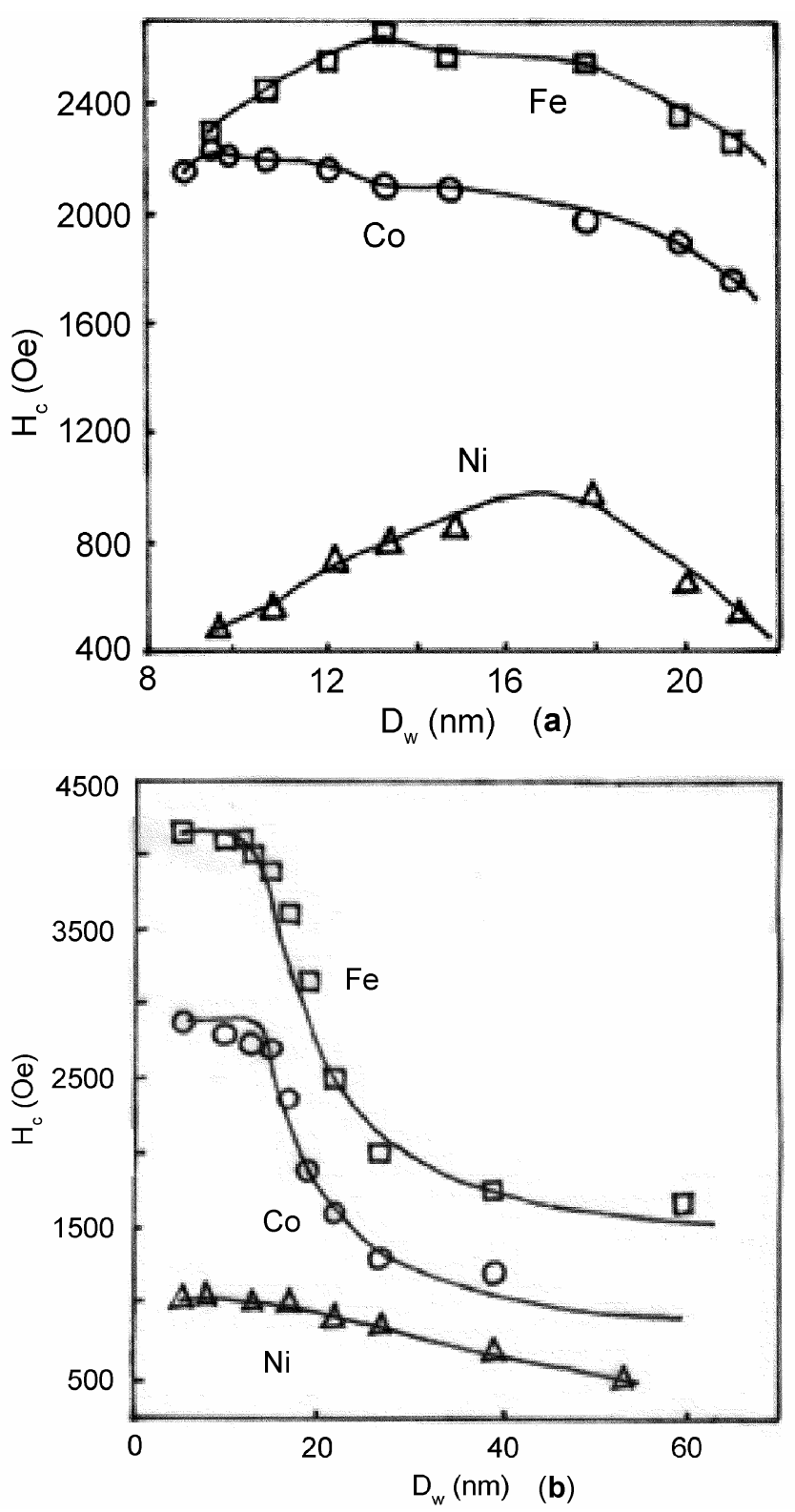

Figure 2. Coercivity as a function of nanowire diameter $\left(D_{\mathrm{w}}\right)$ for magnetic nanowires of $\mathrm{Fe}, \mathrm{Co}$ and $\mathrm{Ni}$ at (a) room temperature and (b) at zero-temperature (Zeng et al 2002). 
anisotropy, form of the nanowires and the demagnetization fields between the nanowires.

Hexagonally arranged Ni-nanowires embedded in anodic alumina templates have been found to exhibit a strong enhancement in their magnetooptical (MO) response (Peng et al 2003). It has been reported (Nielsch et al 2001) that the magnetic nanowires of $\mathrm{Fe}, \mathrm{Co}, \mathrm{Ni}$ show much enhanced magnetic coercivity than that of their bulk counterpart. It is important to note that the coercivity is strongly influenced by annealing of the wire at different temperatures,
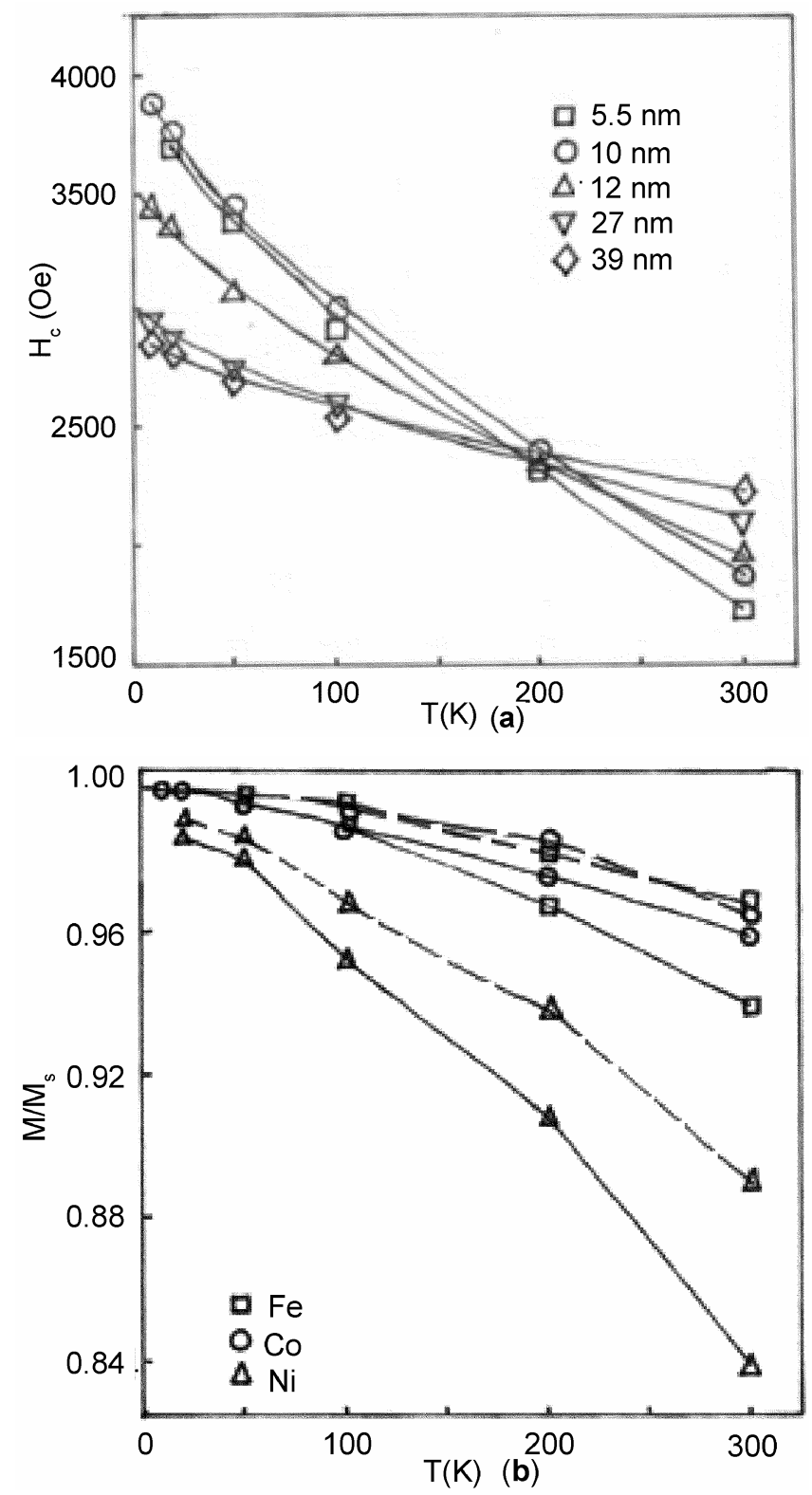

Figure 3. Variation of (a) coercivity as a function of temperature with different diameters of Fe nanowires and (b) magnetization as a function of temperature for different diameters of $\mathrm{Fe}, \mathrm{Co}$ and $\mathrm{Ni}$ nanowires. (Solid lines: $5.5 \mathrm{~nm}$ diameter nanowires, dashed line: $10 \mathrm{~nm}$ diameter nanowires (Zeng et al 2002)). the aspect ratio and the wire diameter. Figures 2(a) and (b) show coercivity of the magnetic $\mathrm{Fe}, \mathrm{Co}$ and $\mathrm{Ni}$ nanowires with their diameters at room temperature and at zero temperature. The temperature dependence of coercivity as a function of wire diameter of $\mathrm{Fe}$ nanowires is shown in figure 3(a) and the variation of saturation magnetization as a function of temperature for different diameters of $\mathrm{Fe}, \mathrm{Co}$ and $\mathrm{Ni}$ nanowires are shown in figure 3(b).

Studies on the magnetoresistance (MR) property of nanowires provide a lot of information on the quantization effect, wire boundary scattering of electrons and the effect of doping and annealing on scattering (Heremans et al 1998). Zhang et al (1998a) studied the MR properties of $\mathrm{Bi}$ nanowires in detail. It has been reported (Heremans et al 1998, 2000; Zhang et al 1998a; Lin and Dresselhaus 2002) that the longitudinal MR, where the magnetic field is applied along the wire axes, the MR peak maxima at a
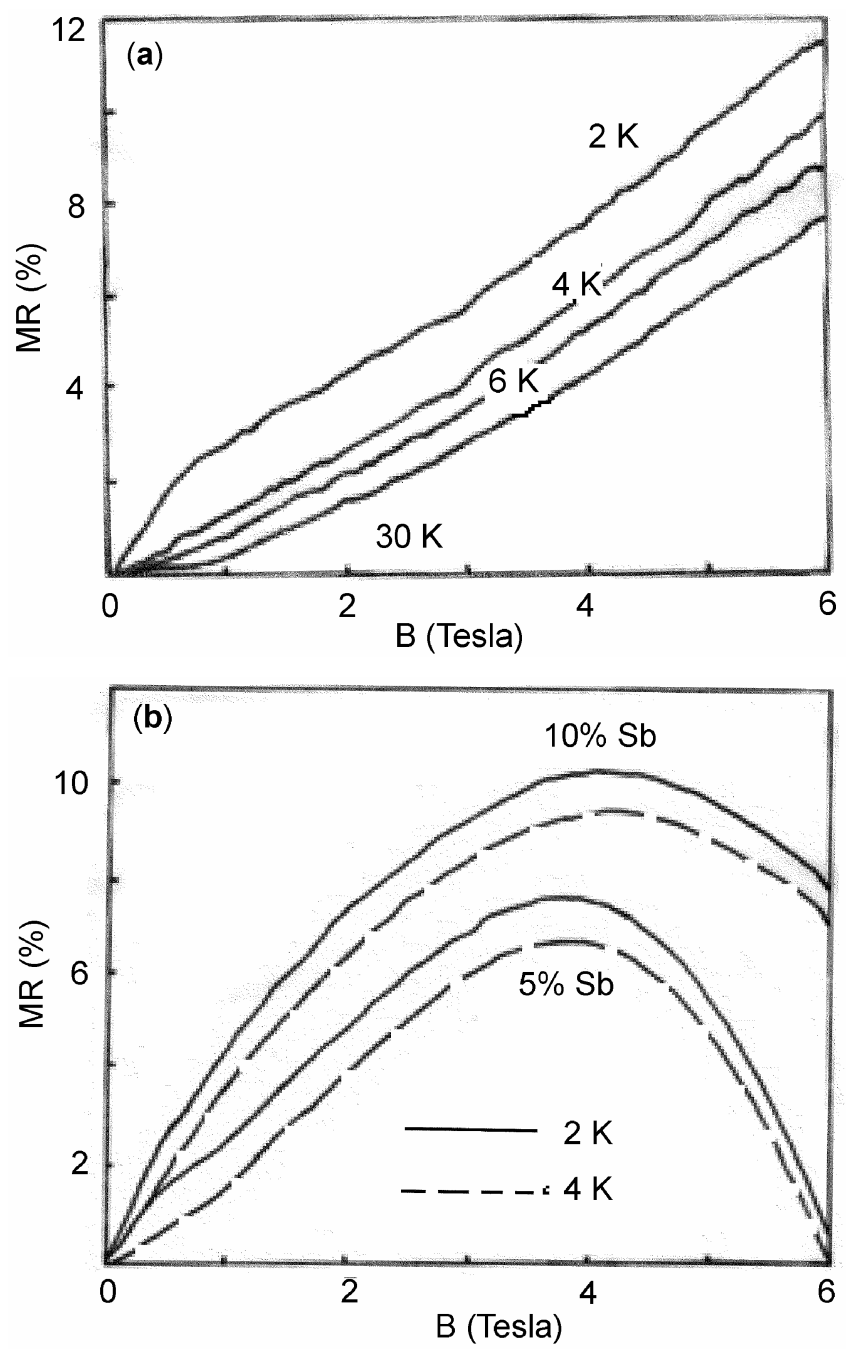

Figure 4. Longitudinal MR of (a) $40 \mathrm{~nm}$ diameter $\mathrm{Bi}_{0.85} \mathrm{Sb}_{0.15}$ alloy nanowires and (b) $65 \mathrm{~nm}$ diameter $\mathrm{Bi}-\mathrm{Sb}$ alloy nanowires as a function of magnetic field, $B$, at different temperatures (Zhang et al 2000). 
particular applied field $(B)$ varies linearly with the reciprocal of the wire diameter for a specified temperature. The appearance of the maxima is attributed to the classical size effect. On the other hand, in transverse MR of $\mathrm{Bi}$ nanowires, where the magnetic field is applied perpendicular to the wire axis, the temperature follows $T \propto B^{2}$ in the range of $0 \leq B \leq 5 \cdot 5 T$.

It has been found that the MR of nanowires is highly diameter dependent. The longitudinal MR as a function of magnetic field for $\mathrm{Bi}_{0.85} \mathrm{Sb}_{0.15}$ alloy nanowires with $40 \mathrm{~nm}$ diameter at different temperatures are quite linear as shown in figure 4(a). On the other hand, $65 \mathrm{~nm}$ diameter $\mathrm{Bi}_{1-x} \mathrm{Sb}_{x}$ nanowires exhibit different types of longitudinal MR as a function of the applied field as can be seen in figure 4(b). The maxima in MR are attributed to the boundary scattering effect (Zhang et al 2000).

It has been reported (Heremans et al 1998) that the 1-D confined system at low magnetic field can be transformed into 3-D confined system by applying a longitudinal magnetic field to the nanowire arrays at very low temperatures. The Bi nanowires of diameter up to $200 \mathrm{~nm}$ show the Shubnikow-de Hass ( $\mathrm{SdH})$ oscillating effect, which appears because of the field strength variation when the quantized Landau level passes through the Fermi energy level (Heremans and Thrush 1999).

1.1a Applications: The most attractive potential applications of nanowires lie in the magnetic information storage medium. Studies have shown that periodic arrays of magnetic nanowire arrays possess the capability of storing $10^{12} \mathrm{bits} / \mathrm{in}^{2}$ of information per square inch of area. The small diameter, single domain nanowires of $\mathrm{Ni}$, Co fabricated into the pores of porous anodic alumina (ThurnAlbrecht et al 2000; Nielsch et al 2001) has been found to be most suitable for the above purpose. The high aspect ratio of the nanowires results in enhanced coercivity and suppresses the onset of the 'superparamagnetic limit', which is considered to be very important for preventing the loss of magnetically recorded information between the nanowires. Suitable separation between the nanowires is maintained to avoid the inter-wire interaction and magnetic dipolar coupling. It has been found that nanowires can be used to fabricate stable magnetic medium with packing density $>10^{11}$ wires $/ \mathrm{cm}^{2}$.

\subsection{Thermoelectric properties}

Nanowires exhibit interesting thermoelectric properties. The unique electronic band structure and diameter dependent variation in electron density of state make nanowires promising materials for various thermoelectronic applications (Hicks and Dresselhaus 1993; Heremans et al 1998). Metal nanowires exhibit many fold increase in Seebeck coefficient due to their enhanced density of electronic states at the one-dimensional sub-band edges, which is attributed to the quantum confinement effect. Here it would be worthwhile to mention that the thermopower of the metallic nanowires also increases because of the enhanced electronic density of state near the Fermi energy level. Studies have shown that the Seebeck coefficient and thermopower of metallic nanowires are significantly influenced by the wire diameter and the alloy phase concentration. It is also observed that the thermal conductivity of nanowires is influenced by the wire diameter. The variations of thermal conductivity $(k)$ as a function of temperature for Si nanowires of different diameters are shown in figure 5 .

It has been reported (Heremans et al 2002; Lin et al 2002) that in Sb and Si doped Bi nanowires, the thermopower can be increased by decreasing the wire diameter. A similar phenomenon has also been observed in case of alumina doped $\mathrm{Zn}$ nanowires (Heremans et al 2002). Bi nanowires also exhibit significant temperature $(T)$ dependence of resistance, $R(T)$, and the phenomena is strongly influenced by the variation of diameter of the nanowires (Heremans et al 2000). Here it should be noted that the Bi nanowires exhibit quantum confinement effect below certain critical diameter $(\sim 48 \mathrm{~nm})$ and the semimetallic phase of Bi transforms into the semiconducting phase (Heremans et al 2000, 2002; Lin et al 2000). This phenomenon implies that at elevated temperature or at room temperature, the semimetallic phase transformation of $\mathrm{Bi}$ nanowires is possible only by reducing the wire diameter. The crystalline structure of the material is also an important factor, which influences the quantum size effect of nanowires. In polycrystalline nanowires, the resistance maxima that can

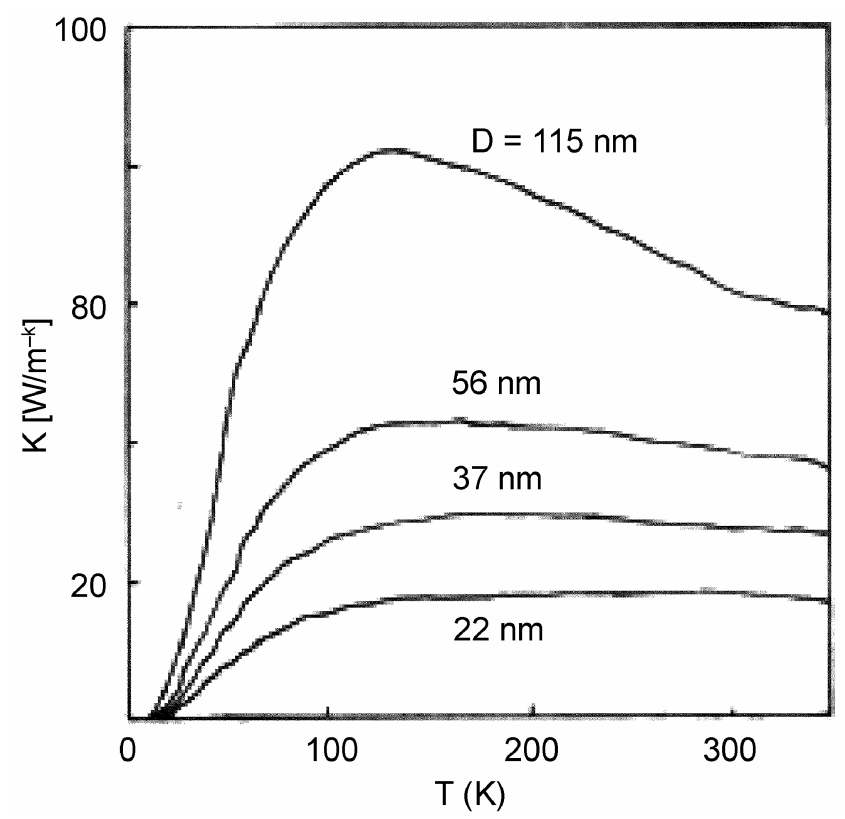

Figure 5. Thermal conductivity $(k)$ as a function of temperature for Si nanowires of different diameters $(D)$ (Dames and Chen 2002) 
be normally observed in $R(T)$ vs $T$ curve is not observed because of less carrier mobility due to the boundary scattering effect (Lin et al 2002). Plots of $R(T) / R(270 \mathrm{~K})$ ratio measured as a function of temperature, $T(K)$, for $40 \mathrm{~nm} \mathrm{Bi}$ and Te doped $\mathrm{Bi}$ nanowires are shown in figure $6(\mathrm{a})$. The average carrier mobility ratio, $\mu(T) / \mu(270 \mathrm{~K})$, for the same nanowires were also calculated from the $R(T)$ value and the $T$-dependent carrier density measurement. Figure 6(b) shows the temperature dependence of mobility ratio, $\mu(270 \mathrm{~K}) / \mu(T)$, where $N_{\mathrm{d}}$ stands for the doped Te ion concentration (ions $/ \mathrm{cm}^{3}$ ).

Investigations have clearly shown that the electronic wave function becomes more localized with the reduction of diameter of the nanowires (Beutler and Giordano 1988; Venkatasubramanian et al 2001; Heremans et al 2002).
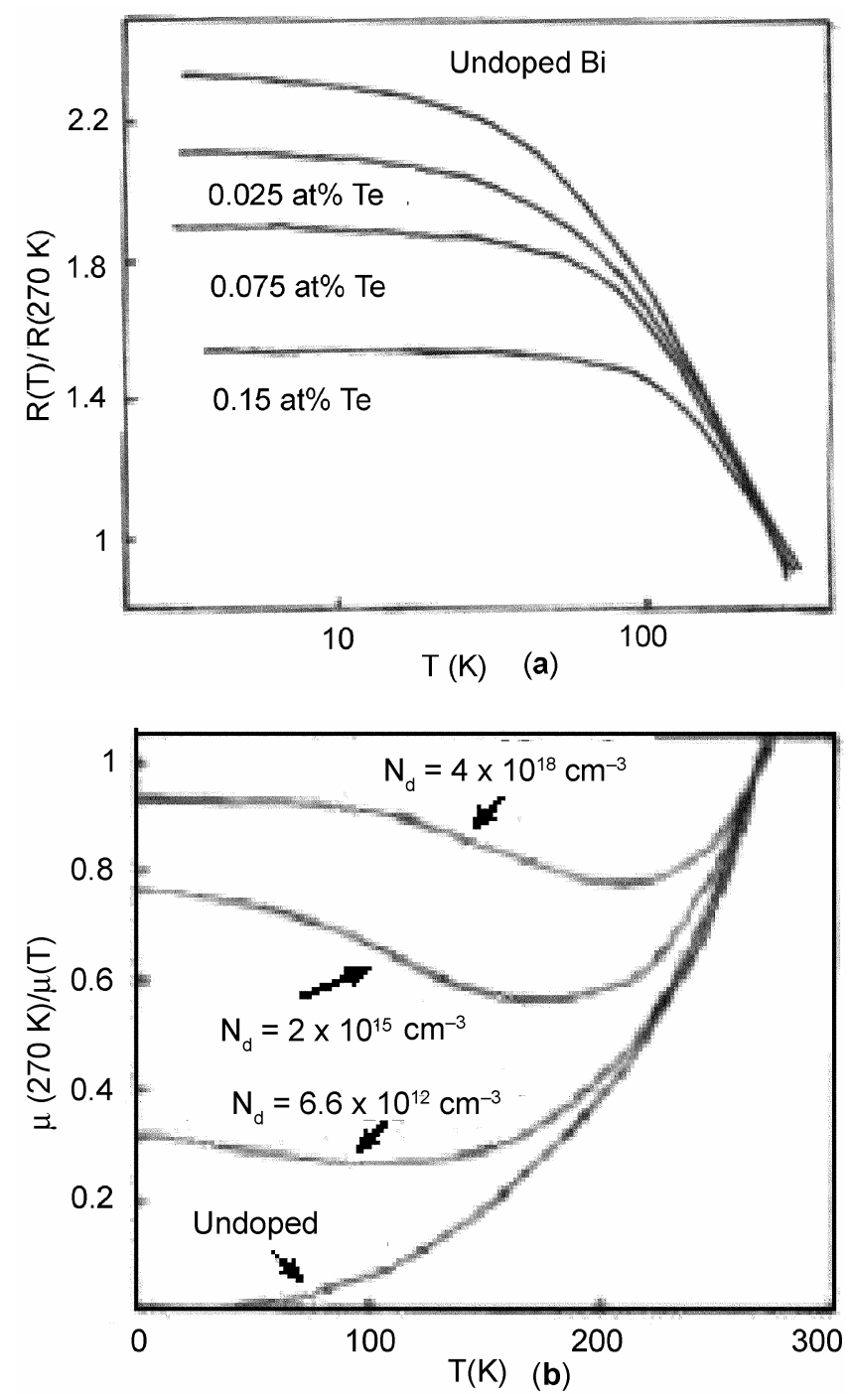

Figure 6. (a) The $R(T) / R(270 \mathrm{~K})$ of $40 \mathrm{~nm}$ diameter Bi nanowires with different amounts of Te alloy concentrations (Lin et al 2000) and (b) carrier mobility ratio as a function of temperature of $40 \mathrm{~nm}$ Bi nanowires with different doped Te atom concentration (Lin et al 2000).
This phenomenon is considered to be the key factor that causes nanowires to exhibit interesting thermoelectric properties.

1.2a Applications: The enhanced thermopower and manyfold increase in the Seebeck coefficient of nanowires make them very attractive for thermoelectric cooling system and energy conversion devices (Dresselhaus et al 1998; Chen et al 2003).

\subsection{Electrical properties (transport properties)}

Electron transport properties of nanowires are very important for electrical and electronic applications as well as for understanding the unique one-dimensional carrier transport mechanism. It has been noticed that the wire diameter, wire surface condition, crystal structure and its
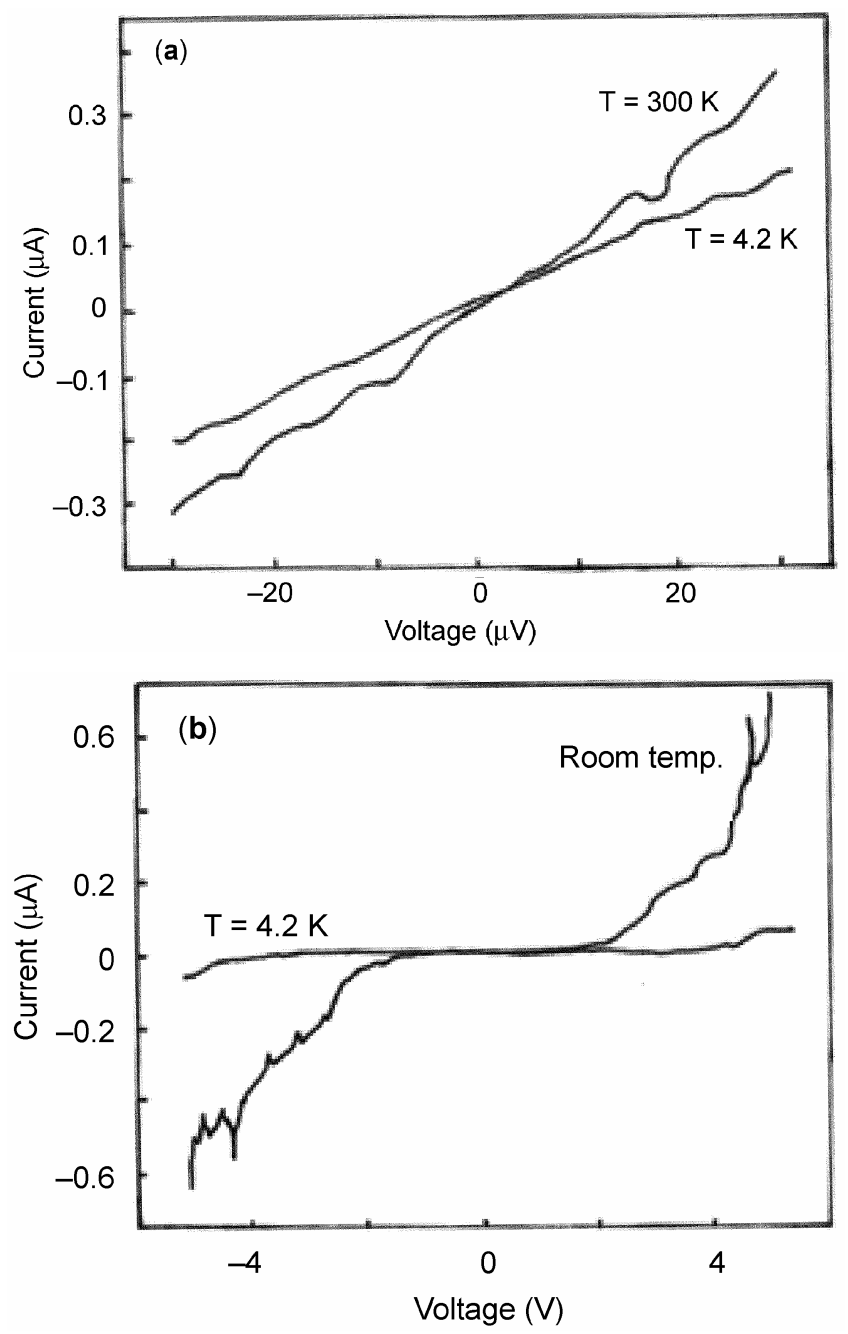

Figure 7. (a) $I-V$ characteristics of the metallic $\mathrm{Cu}$ nanowire at $4.2 \mathrm{~K}$ and at room temperature and (b) $I-V$ curves of the wire at $4.2 \mathrm{~K}$ and room temperature recorded after oxidation of $\mathrm{Cu}$ nanowires (Molaresa et al 2003). 
quality, chemical composition, crystallographic orientation along the wire axis etc are important parameters, which influence the electron transport mechanism of nanowires. Figure 7 (a) shows the $I-V$ characteristics of the $\mathrm{Cu}$ nanowires both at room temperature and at $4.2 \mathrm{~K}$. The plot clearly shows the linear ohmic behaviour. However, by oxidation when the metallic $\mathrm{Cu}$ nanowires are transformed into semiconducting $\mathrm{Cu}_{2} \mathrm{O}$ nanowires and placed between two electrodes, it forms two Schottky diodes in series and a double diode like $I-V$ characteristic curve is obtained as shown in figure 7(b).

It has been reported that quasi one-dimensional nanowires exhibit both ballistic and diffusive type electron transport mechanism, which depends upon the wire length and diameter. Ballistic type transport phenomena is associated with predominant carrier flow without scattering which is due to the fact that the carrier mean free path is longer than that of the wire length (Bhushan 2005). Ballistic type transport mechanism is normally observed at the contact junction of nanowire and other external circuits (Muller et al 1992, 1996), where the conductance is quantized into an integral multiple of $2 e^{2} / h$, called the universal conductance unit ( $e$ is the electronic charge and $h$ the Plank's constant) (van Wees et al 1988; Wharam et al 1988).

In the case of ballistic type transport in metallic nanowires, the conductance quantization phenomena takes place because of the fact that the nanowire diameter becomes comparable to the electron Fermi wavelength of that metal (Costa-Krämer et al 1997). As compared to the ballistic transport mechanism, in diffusive type conduction mechanism, the carrier mean free path is smaller than that of the wire length. Therefore, various types of scattering affect the carriers and the carrier transport mechanism of nanowires becomes quite similar to that of bulk counterpart.

The clearest view of the electron transport mechanism of the metallic and semiconducting nanowires can be easily obtained by considering three parameters viz. wire diameter $(d)$, carrier mean free path $\left(l_{\mathrm{c}}\right)$ and the de Broglie wavelength of electron $\left(\lambda_{\mathrm{e}}\right)$. Earlier studies have shown that when the wire diameter $(d)$ is larger than the carrier mean free path $\left(l_{\mathrm{c}}\right)$ and the de Broglie wavelength of electron $\left(\lambda_{\mathrm{e}}\right)$ i.e. $d>>l_{\mathrm{c}}$ and $d>>\lambda_{\mathrm{e}}$, the electron transport mechanism of nanowires remains similar to that of bulk counterpart. However, if the wire diameter $(d)$ becomes smaller or comparable to that of the carrier mean free path $\left(l_{\mathrm{c}}\right)$ and much larger than the de Broglie wavelength of electron $\left(\lambda_{\mathrm{e}}\right)$ i.e. $d \leq l_{\mathrm{c}}$ and $d>>\lambda_{\mathrm{e}}$, the electron transport mechanism of nanowires follows the classical laws of physics. On the other hand, when the carrier mean free path $\left(l_{\mathrm{c}}\right)$ and the de Broglie wave length of electron $\left(\lambda_{\mathrm{e}}\right)$ both become comparable to the wire diameter i.e. $d \leq l_{\mathrm{c}}$ and $d \sim \lambda_{\mathrm{e}}$, the phenomena of quantum confinement occurs in nanowires which includes significant change in the density of electron states. Studies show that the electronic density of states
(DOSs) of nanowires is strongly diameter dependent. For example, electronic DOSs of $\mathrm{Ti}$ nanowires of diameter $<1 \mathrm{~nm}$ exhibit some discrete peaks like molecules as shown in figures 8(a) and (b). Thicker Ti nanowires (diameter, $>1 \mathrm{~nm}$ ) show bulk Ti like electronic DOSs, because of the formation of continuous electronic bands caused by the overlapping of discrete molecular levels with each other as shown in figures 8(c) and (d).

However, it is found that the conductance of nanowires strongly depends on their crystalline structure. For example, in the case of perfect crystalline Si nanowires having four atoms per unit cell, generally three conductance channels are found (Zhao et al 2003). One- or two-atom defect, either by addition or removal of one or two atoms may disrupt the number of such conductance channel and may cause variation in the conductance. Variation in conductance due to the above reason is shown in figure 9, where conductance is plotted as a function of energy for perfect $\mathrm{Si}$ nanowires and single atom addition defect nanowire.

It is to be noted that change in the surface conditions of the nanowires can cause remarkable change in the transport behaviour. This has been illustrated in figure 10, where it can be seen that change in electrical conductivity has been caused by the variation of the surface scattering phenomena of carriers in nanowires, when the diameters of the nanowires are changed.
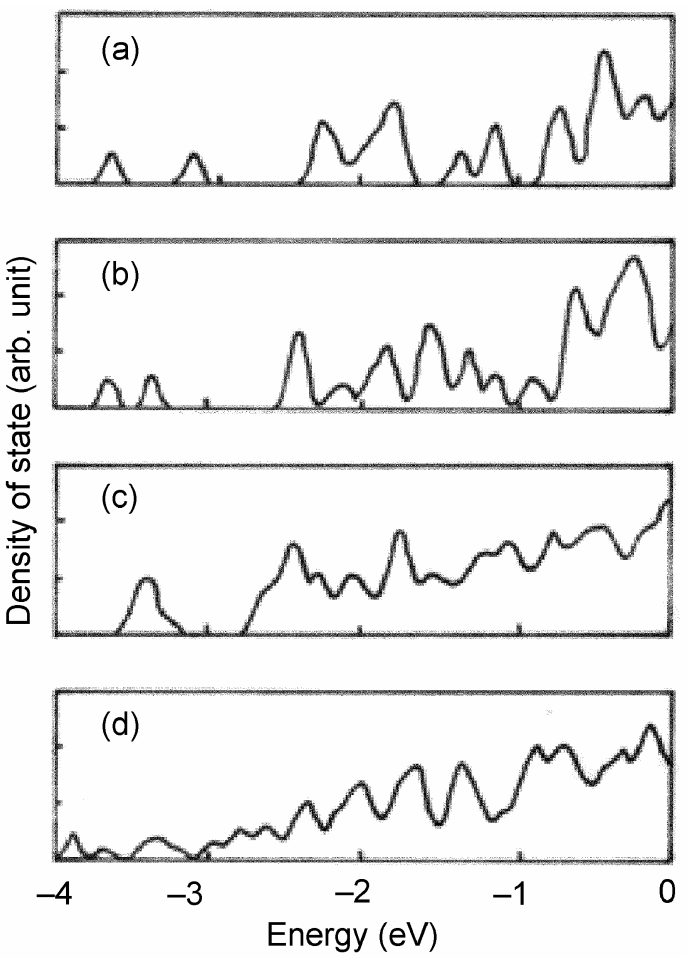

Figure 8. Electronic densities of states (DOSs) of Ti nanowires: (a) and (b) wire diameter $<1 \mathrm{~nm}$ and (c) and (d) wire diameter $>1 \mathrm{~nm}$ with $0.05 \mathrm{eV}$ Gaussian broadening. The Fermi level is set as zero on the energy axis (Wang et al 2001). 
It has also been reported (Duan et al 2002) that the redox molecules like cobalt phthalocyanine layer coating on the $n$-InP nanowires change their conductance remarkably. Researchers have shown that the resistance of Pd nanowires changes by an order of magnitude due to the adsorption of hydrogen gas molecules on the wire surface.

Recently, electron transport mechanism of superlattice nanowires has acquired lot of interest because of their potential applications in thermoelectronics (Lin and

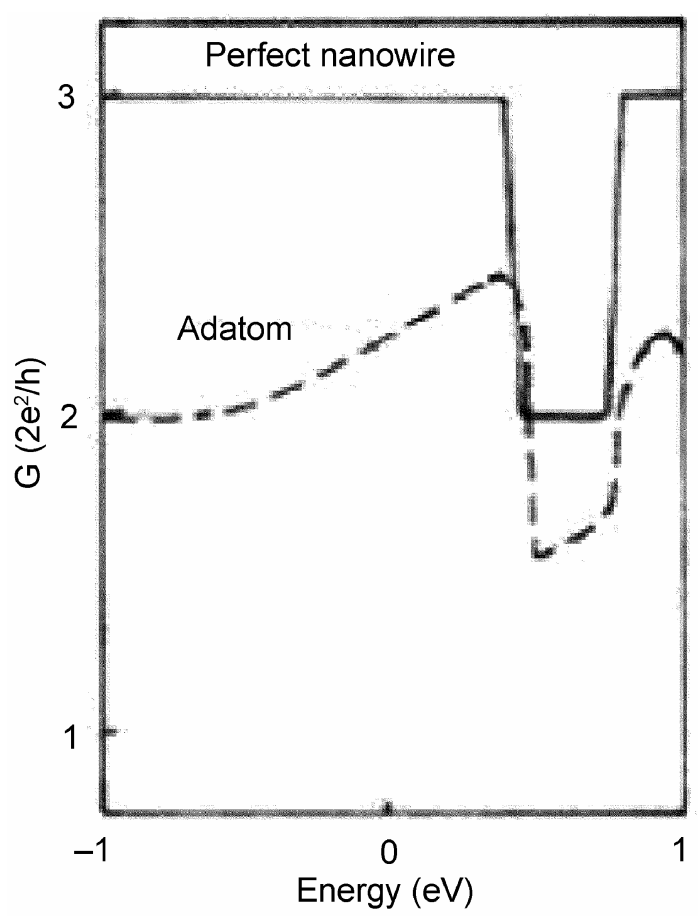

Figure 9. Conductance, $G\left(2 e^{2} / h\right)$ of silver nanowires with single-atom defects: Adatom (dotted line) and for perfect nanowires (solid curve) (Zhao et al 2003).

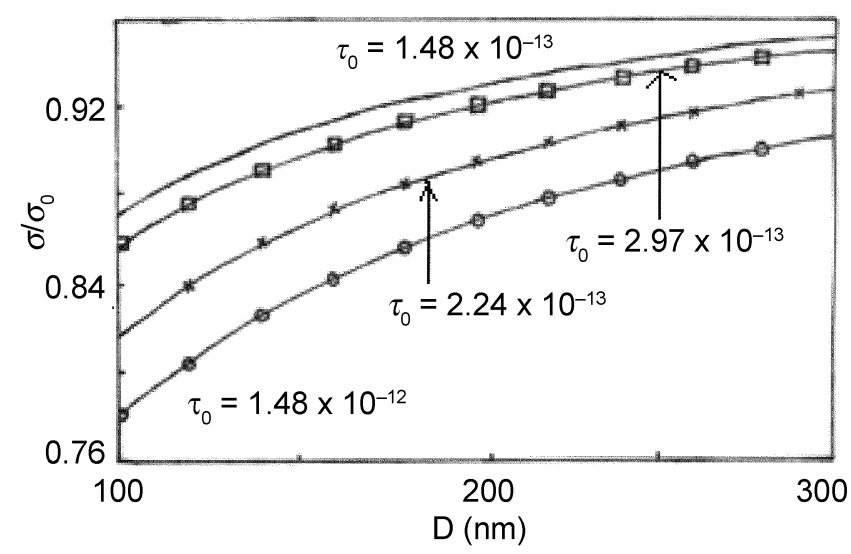

Figure 10. Relative conductivity vs nanowire radius $(D)$, at $300 \mathrm{~K}$, where $\sigma_{0}$ is the bulk conductivity corresponding to scattering time, $\tau_{0}$ (in s) (Redwing et al 2002).
Dresselhaus 2003), nanobarcodes (Wu et al 2002), nanolasers (Gudiksen et al 2002), one-dimensional waveguide and resonant tunneling diodes (Björk et al 2002a, b). Superlattice nanowires consist of periodic modulation of chemical composition and crystal structure in the form of quantum dots along the wire axes. The electron transport phenomena between those quantum dots are governed by the quantum tunneling mechanism in which specific regions of the nanowires with a particular composition act as the potential barrier. As for example, in case of the InAs-InP superlattice nanowires the InP dots act as the potential barrier (Björk et al 2002a, b). It is to be noted that the interfaces between the quantum dots have the capability of blocking the phonon conduction along the wire axes without affecting the electrical conduction.

1.3a Applications: Nanowires possess the potential for use in numerous electronic applications. Junctions of semiconductor nanowires such as $\mathrm{GaAs}$ and $\mathrm{GaP}$ have shown good rectifying characteristics (Gudiksen et al 2002). Several semiconductor devices such as junction diodes (Huang et al 2001; Kim et al 2002), memory cells and switches (Duan et al 2002), transistors, FETs (Huang et al 2001; Duan et al 2002), LEDs (Duan et al 2001; Gudiksen et al 2002) and inverter (Derycke et al 2001) etc have already been fabricated using nanowire junctions. Figure 11(a) shows a schematic diagram of FET made of nanowires. The LED fabricated by a crossed junction of $p$-Si and $n$-GaN with their $I-V$ characteristics and EL spectra are shown in figures 11(b) and (c), respectively. These basic building blocks of semiconductor devices can be used to fabricate complex IC chips of much reduced dimension.

It has been found that these junction devices exhibit transport and current rectifying properties similar to their parent counterpart. Several attempts have been made to fabricate nanowire diode and it has been demonstrated that the crossings of phosphorus $(n)$ and boron $(p)$ doped Si nanowires form $p-n$ junction diodes (Cui et al 2001). Similar type of junction diode can also be formed by $n$ and $p$ type InP nanowires (Duan et al 2001). Figures 12(a) and (b) show an in-plane gate (IPG) quantum wire transistor (QWRTr) and a warp gate (WPG) quantum wire transistor made of GaAs nanowires, respectively. A WPG QWR-based binary decision diagram (BDD) device is shown in figure 12(c) and figure 12(d) represents the SEM image of hexagonal BDD 2 bit digital Adder circuit.

The field effect transistors made of nanowires exhibit remarkably modified conductance behaviour (Chung et al 2000; Cui et al 2000; Huang et al 2002) and they are very attractive because of their morphological advantages. The operational speed of FETs made of nanowires is much faster compared to that of bulk FETs.

In contrast to the crossing of two distinctive nanowires, several heterogeneous junctions can be formed inside single superlattice nanowire, by varying the materials 
compositions along the wire axes (Gudiksen et al 2002) or perpendicular to the wire axes (Lauhonn et al 2002).

Nanowire junctions can also perform certain logical operations and can be used as logic gates (Huang et al 2001; Duan et al 2002) (see figure 13). The electroluminescence (EL) properties of nanowires can be employed for different opto-electronic applications (Duan et al 2001). For example, figure 14(a) represents three crossed junctions made of $p$-Si nanowire with $n$-GaN, $n$-CdS and $n$-CdSe nanowires and their corresponding EL spectral peak (figure 14(b)).

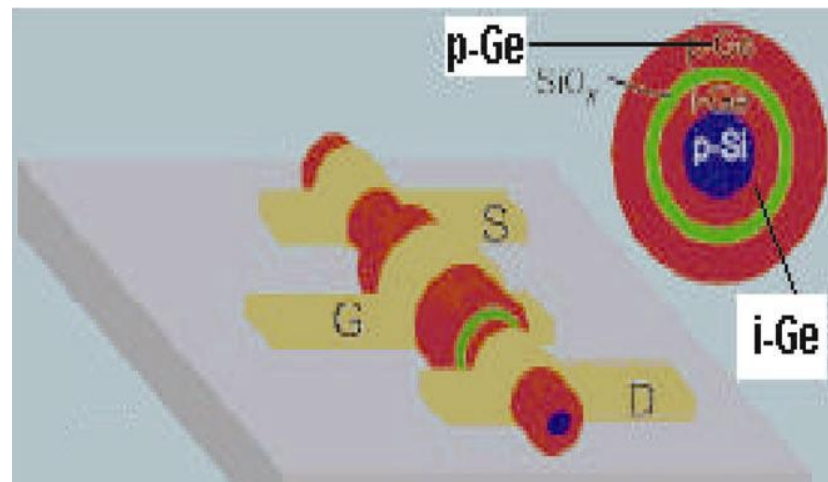

(a)
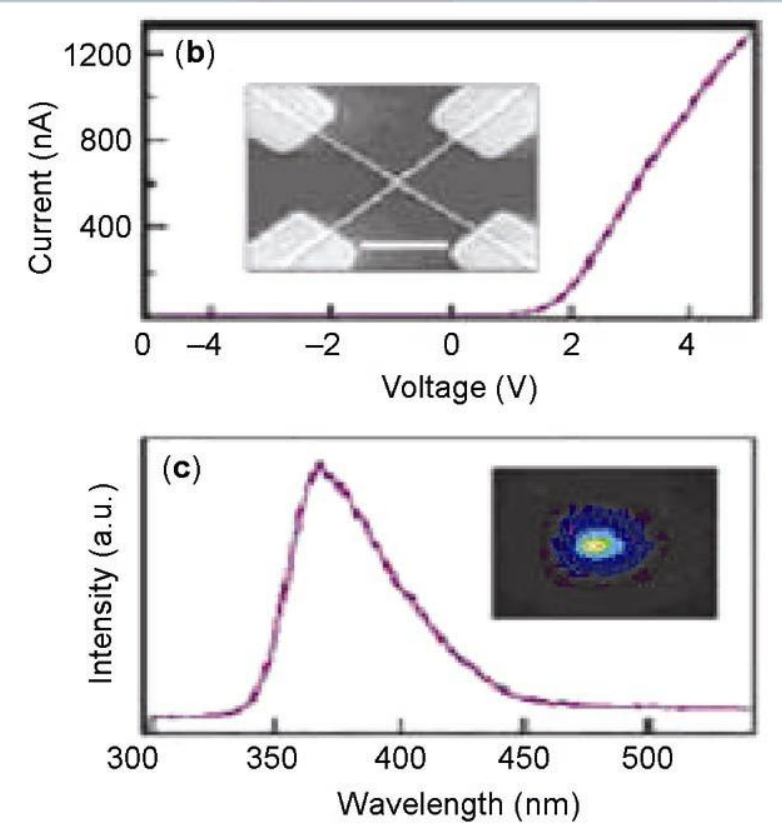

Figure 11. (a) Schematic representation of a coaxially fabricated nanowire FET. Inset: Cross sectional view of FET with layers of $i$-Ge (red, $10 \mathrm{~nm}), \mathrm{SiO}_{2}$ (green, $4 \mathrm{~nm}$ ), and $p$-Ge $(5 \mathrm{~nm})$. The source $(S)$, drain $(D)$ and gate $(G)$ electrodes are also shown, (b) $I-V$ characteristics of a $p-\mathrm{Si} / n-\mathrm{GaN}$ crossed junction LED. Inset: Scanning electron microscopic (SEM) image of the junction LED (Huang et al 2005) and (c) EL spectra of the LED. Inset: EL image representing the spatial of intensity having a maximum at the crossed junction (Huang et al 2005)
Nanowire arrays can be used in field emission devices such as flat panel displays (Ding et al 1999) because of the significant drop in the work function of the surface electrons in those small diameter and high curvature tips of the nanowires (Au et al 1999).

\subsection{Optical properties}

The optical properties of nanowires have been studied extensively by employing different optical characterization and analytical techniques. The complex dielectric function $\left(\varepsilon_{1}+\varepsilon_{2}\right)$ of the nanowires which are embedded in the host material are deduced with the help of effective medium theories (Garnett 1906; Aspnes 1982; Cardona 1982; Yu and Cardona 1995) by considering the nanowires and the host matrix to act as a single material. The refractive index $(n)$ and the absorption coefficient $(k)$ of the medium are related to $\varepsilon_{1}$ and $\varepsilon_{2}$, respectively for the composite medium. The complex dielectric function of the nanowires can also be determined directly with the help of standard reflection and transmission measurements combined with Maxwell's equations (Black et al 2002). The band gap and temperature variation of band gap of the nanowires can be determined from the complex refractive index measurements (Lee et al 2001), which are considered to be important parameters for selection of materials for particular photonic applications. Information about plasmon frequency, donor atom concentration and carrier concentration of nanowires can be obtained by analysing the infrared (IR) spectra of the nanowires.

Metallic nanowires exhibit interesting plasmon absorption effect. Research has shown that the energy of the surface plasmon band is sensitive to various factors such as particle size, shape, composition, surrounding media and inter particle interactions (Kerker 1969; Bohreu and Huffman 1983; Foss et al 1994; Schider et al 2001). It has been reported that changeover from spherical to rod shaped nanostructure of Ag leads to splitting from an original single absorption band to two absorption bands that separate and become very prominent with increasing aspect ratio (Bohreu and Huffman 1983). It has also been found that single crystal Ag nanowire arrays with high aspect ratio exhibit two plasmon absorption bands as shown in figure 15. The first peak arises due to the transverse plasmon resonance and the second peak is attributed to the longitudinal plasmon resonance (Foss et al 1994; Huang et al 1996). Studies on the surface plasmon modes on Ag and Au nanowires have shown the occurrence of multipolar plasmon resonances, which can be explained by the standing plasmon wave considerations (Schider et al 2003). Recently, it has been reported that multiple peaks appear in the plasmon absorption spectra of the sulfide coated gold nanorods (Chatterjee et al 2006).

The photoluminescence (PL) spectroscopic studies on semiconducting nanowires (InP, $\mathrm{CdS}, \mathrm{ZnO}$ nanowires) 

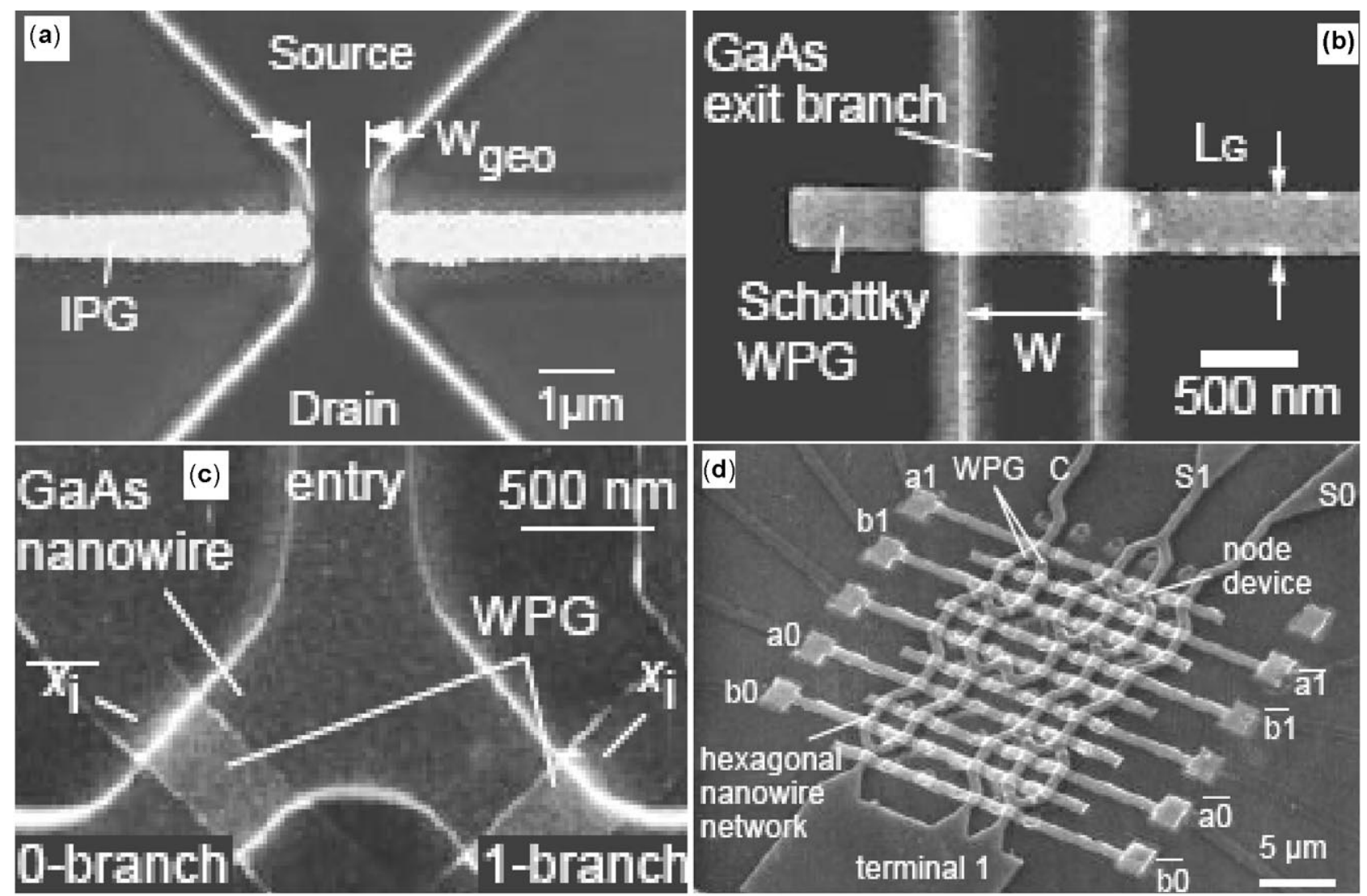

Figure 12. SEM image of (a) IPG QWRTr, (b) WPG QWRTr, (c) WPG QWR-based BDD device and (d) hexagonal BDD 2 bit digital adder (Hasegawa 2001).

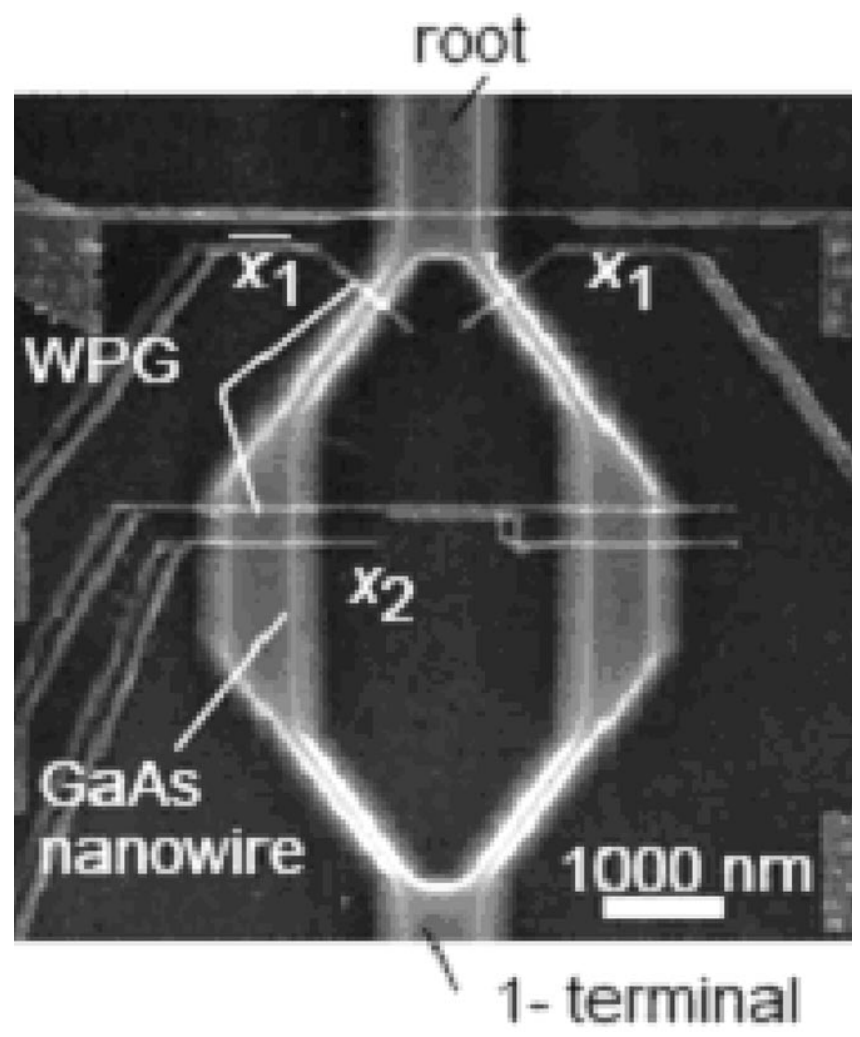

Figure 13. SEM image of a WPG single electron BDD OR logic gate (Hasegawa 2001). (van Vugt et al 2005) have shown that the PL energy peak and band gap increases with the decrease of the wire diameter. The above phenomena confirm the effect of quantum confinement in nanowires when the wire diameter is reduced.

Fluorescence study of nanowires provides vivid information about the band gap, quantum confinement effect, strain in nanowires, oxygen vacancies, electron effective masses and Fermi energies (Gudiksen et al 2002; Lyons et al 2002; Zheng et al 2002). The number of subbands of the nanowires can be measured with the help of magnetooptic techniques. The determination of the number of subbands in nanowires is very important for determining the electron transport properties in them (Blom et al 1998). It is to be noted that magnetic properties of the nanowires can also be determined by the above-mentioned techniques (Sugawara et al 1997; Pierce et al 2002).

Figures 16(a) and (b) show the magneto-optical (MO) spectra of different diameter Ni nanowires. The magnetooptical polar rotation (Kerr rotation) spectra as shown in figure 16(a) reveals that arrays of $35 \mathrm{~nm}$ diameter $\mathrm{Ni}$ nanowires exhibit sharp peak like bulk Ni around $3.4 \mathrm{eV}$, due to an enhancement in the polar rotation. Figure 16(b) shows the corresponding zero magnetic field reflectivity $(\Delta R / R)$ of the nanowires.

Nanowire arrays exhibit non-linear optical properties, which make them very attractive for application as photonic 
material. The sharp increase in the energy of the absorption peak with the decrease of the wire diameter is attributed to quantum confinement effect (Lin et al 2000) and the occurrence of the blue shift. The extinction spectra of silver nanowires with different diameters shown in figure 17 , revealed that for fixed length $(h)$ of the nanowires when the diameter $(d)$ decreases, $\lambda$ shifts towards the
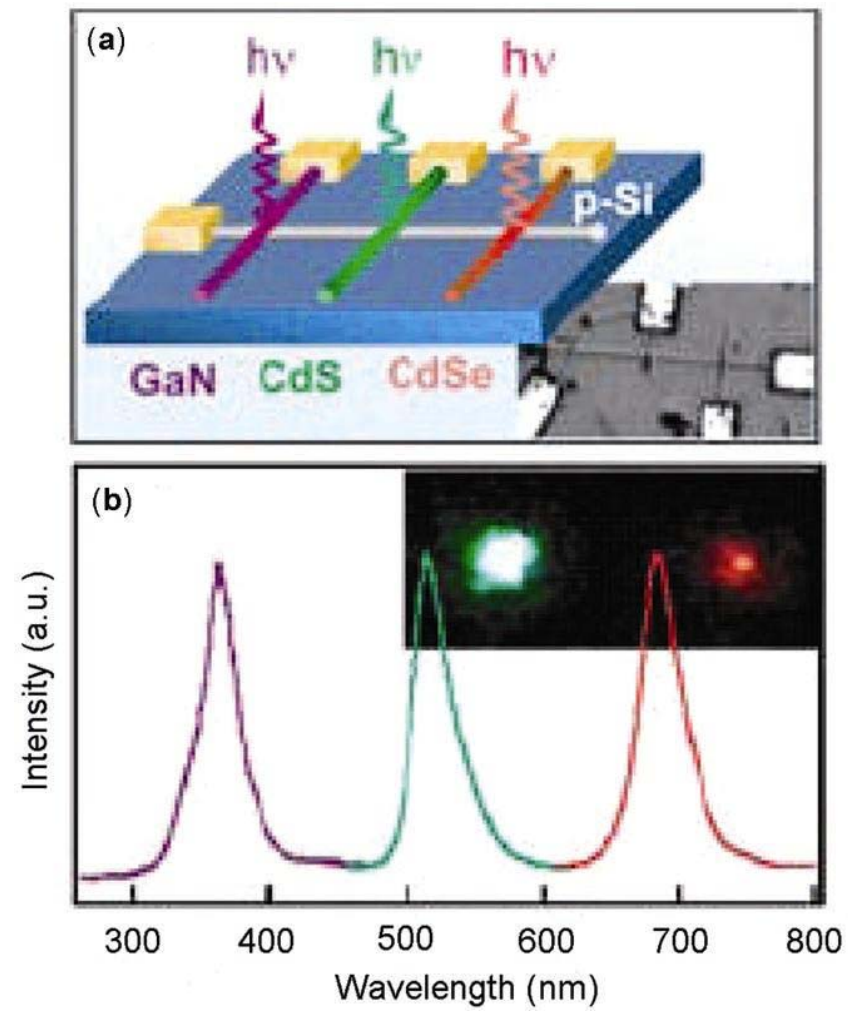

Figure 14. (a) Schematic representation of three crossed junction diodes made of different nanowires. Inset: SEM image of the junction is shown and (b) corresponding EL spectrum from the three junctions are shown (Huang et al 2005).

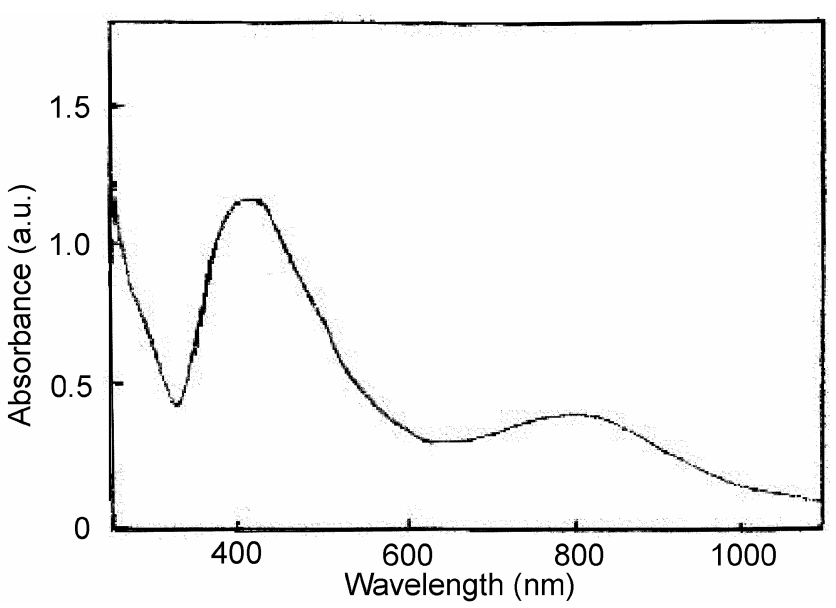

Figure 15. Two plasmon absorption peaks for Ag nanowires (Jiang et al 2001). shorter wavelength side because of the quantum confinement effect.
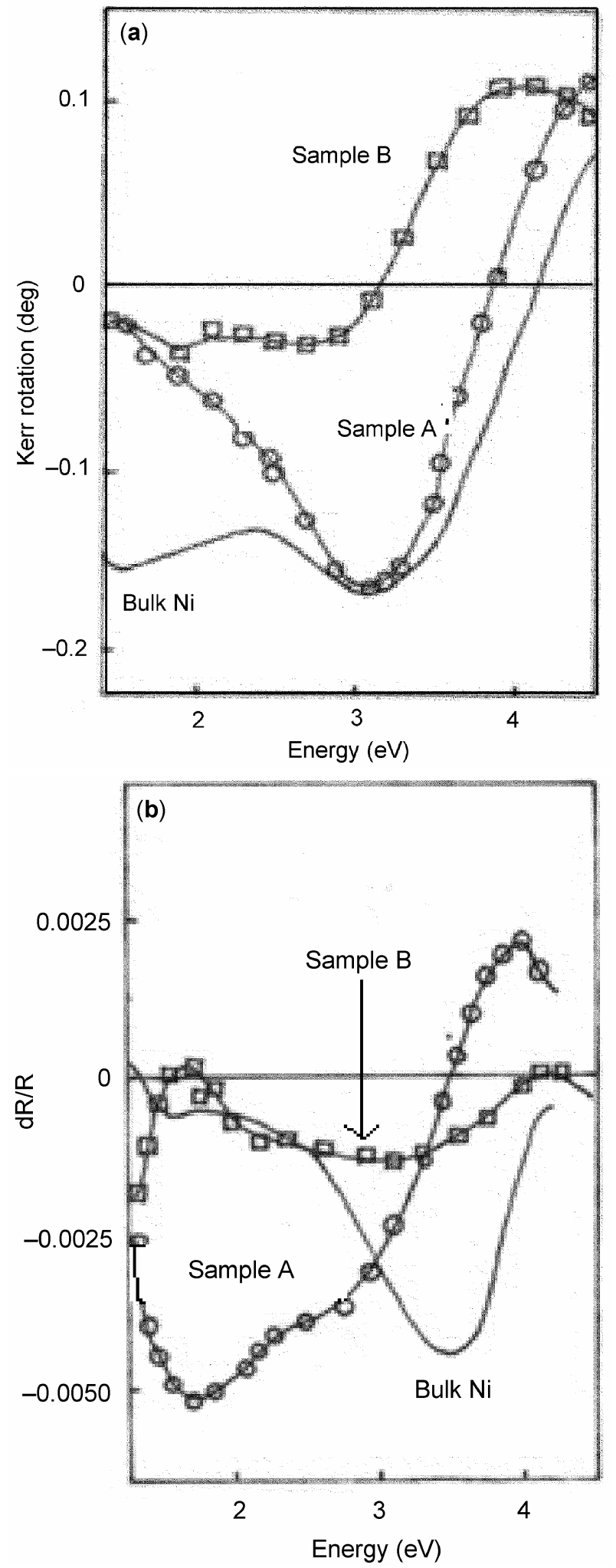

Figure 16. MO polar (a) Kerr spectra and (b) reflectivity comparison between Ni nanowires array and bulk Ni. Samples $A$ and $B$ represent nanowires with diameters $35 \mathrm{~nm}$ and $180 \mathrm{~nm}$, respectively (Melle et al 2003). 
1.4a Applications: Uniform morphology and interesting optical properties of nanowires have raised their potential for various optical applications. The $n-p$ junction of nanowires has been found to be capable of light emission, by virtue of their photoluminescence (PL) or electroluminescence (EL) properties. The use of $p-n$ junction nanowires has been contemplated for laser applications. It has been established that $\mathrm{ZnO}$ nanowires of wire diameter smaller than the wavelength of emitted light exhibits lasing actions (Huang et al 2001a; Johnson et al 2002) at lower threshold energy compared to their bulk counterpart. This has been attributed to the exciton confinement effect in the laser action, which decreases the threshold lasing energy in nanowires. This effect has been observed in small diameter $\mathrm{ZnO}$ (385 nm diameter) and GaN nanowires (Johnson et al 2001, 2002).

The $n-p$ junction nanowires or superlattice nanowires with $p-n$ junctions can also be used as light emitting diodes (Duan et al 2001; Zhao et al 2003). The huge surface area and the high conductivity along the length of nanowires are suitable for inorganic-organic solar cell (Huynh et al 2002). The solar cell made of CdSe nanowires has high efficiency (Wu et al 2002). Very recently the subwavelength diameter Si nanowires have been used as lowloss optical waveguides within visible to near-IR range of spectrum. Studies have shown that the optical losses of those $\mathrm{Si}$ sub-wavelength diameter nanowires are much lower compared to that of other sub-wavelength diameter metallic plasmon waveguides (Takahara et al 1997; Maier

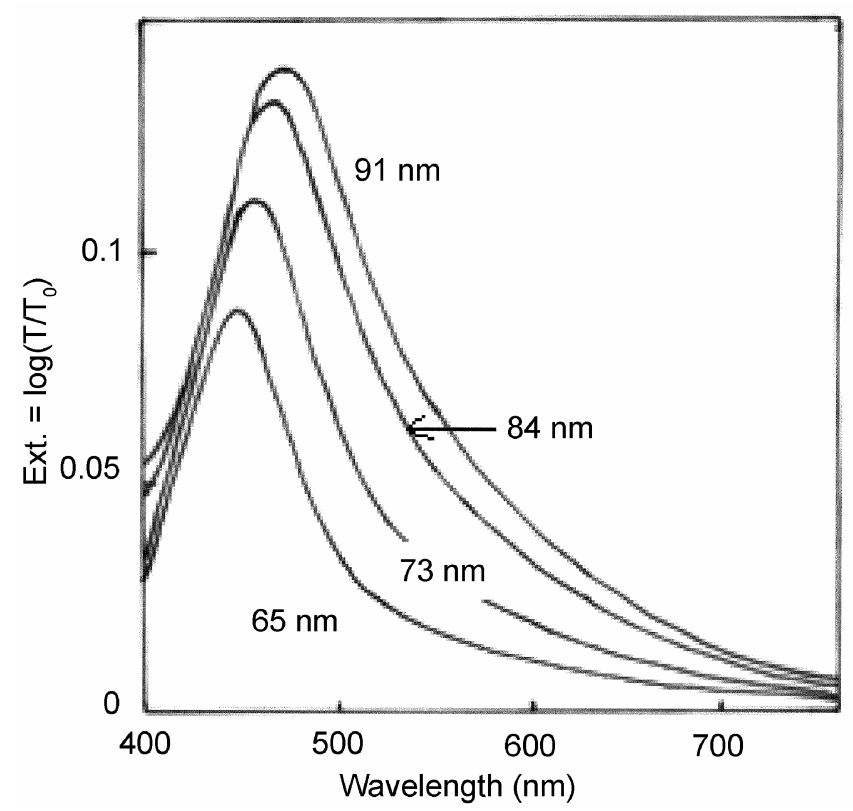

Figure 17. The extinction spectra of different diameter $\mathrm{Ag}$ nanowires are shown. The electric field of the incident light is perpendicular to the wire axes. In this plot $h=50 \mathrm{~nm}, d$ varies from 65-91 nm and $\Lambda=840 \mathrm{~nm}$ (Schider et al 2001). et al 2002, 2003). The optical loss of different diameter Si nanowires transmitting the wavelength of $633 \mathrm{~nm}$ and $1550 \mathrm{~nm}$ are shown in figure 18(a) and figure 18(b) represents a SEM image of a coiled $260 \mathrm{~nm}$ diameter Si nanowire of nearly $4 \mathrm{~mm}$ in length.

Nanowires made of various metal segments like Ag, $\mathrm{Au}, \mathrm{Ni}, \mathrm{Pd}$ etc can be used as barcode tags (Nicewarner et al 2004) for different optical read outs.

It is to be noted that when the intensity of the incident photons are increased the electron density of the subband edges also increases, due to the above fact, these quantum wires develop strong nonlinearity. Therefore, nanowires may be used to develop optical switches. These optical switches will be able to operate at lower energy and with enhanced switching speed compared to the known switches.
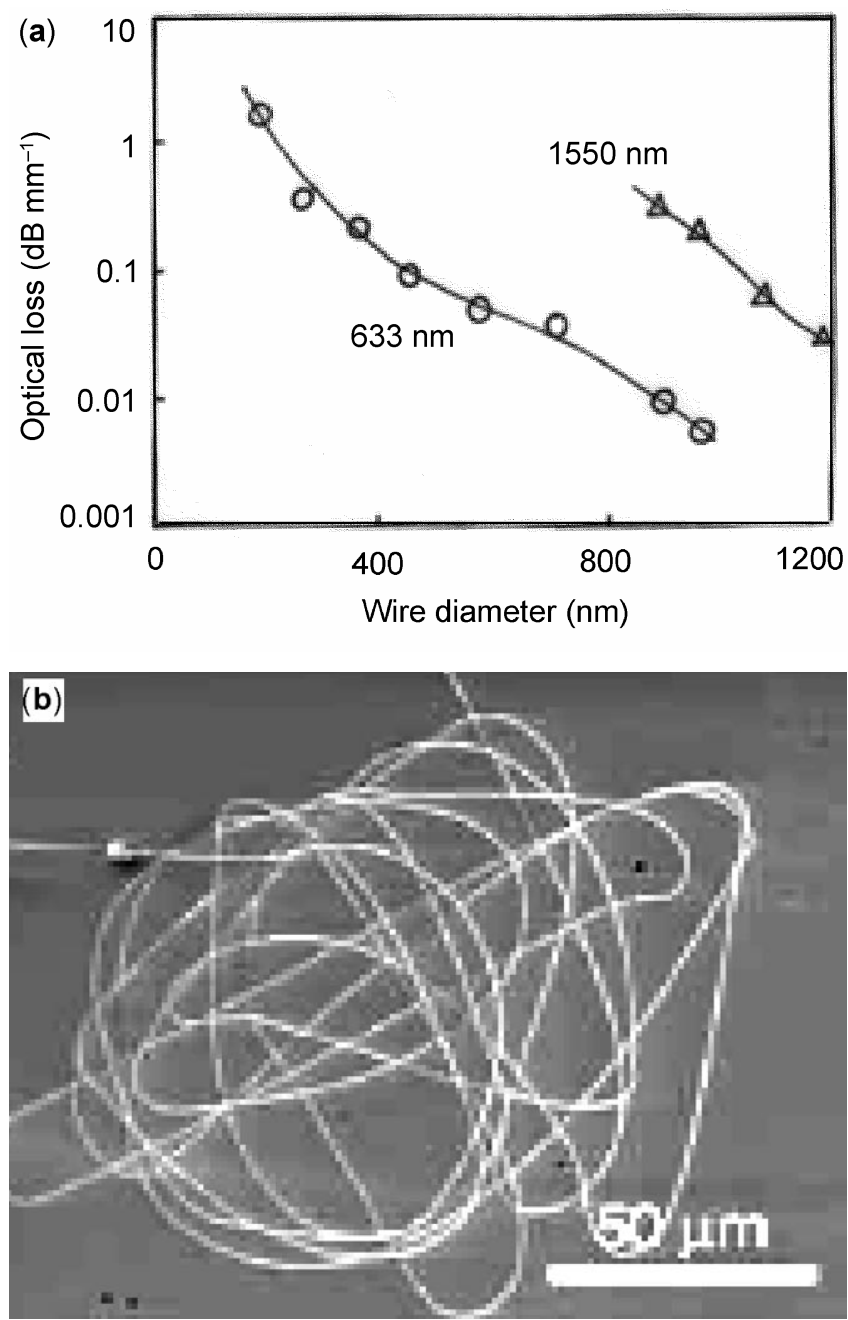

Figure 18. (a) Optical loss of silica wires measured at a wavelength of $633 \mathrm{~nm}$ (filled dark circles) and $1550 \mathrm{~nm}$ (unfilled white circles) (Nicewarner et al 2004) and (b) SEM image of a coiled $260 \mathrm{~nm}$ diameter Si nanowires of length of nearly $4 \mathrm{~mm}$ (Tong et al 2003) 


\subsection{Chemical properties}

Nanowires also exhibit interesting chemical properties mainly because of their enhanced surface to volume ratio, high aspect ratio, large curvature at the nanowire tips and huge number of surface atoms. The high chemical reactivity, interesting electrical and electronic properties of nanowires make them very attractive for sensor devices applications. Figure 19 shows an $\mathrm{Au} / \mathrm{Pt} / \mathrm{Au}$ nanowire with a butaneisonitrile monolayer adsorbed on the wire surface. It is to be noted that all the butaneisonitrile molecules adsorbed to the $\mathrm{Au}$ part of the nanowire can only be replaced by 2-mercaptoethylamine (MEA) when the wire is exposed to MEA because of the enhanced chemical reactivity of Au over Pt.

Chemical and biological sensors made of nanowires as sensing probe exhibit enhanced sensitivity and fast responsivity compared to the conventional sensors, as they need less electrical power to work. It is believed that the capability of providing real space-time distribution of a particular species will be improved significantly if arrays of nanowires are used in the sensing probe. These types of nanowire sensors can also estimate the real concentration of a particular substance quickly. It should be noted that functioning of nanowire-based sensors is based on the principle of change in electrical conductivity, which arises due to the adsorption of the molecules that are required to be detected. This has been illustrated in figure 20,
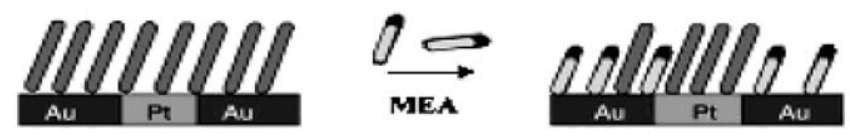

Figure 19. Schematic of an $\mathrm{Au} / \mathrm{Pt} / \mathrm{Au}$ nanowire with a butaneisonitrile monolayer replaced by MEA from all the $\mathrm{Au}$ part of the nanowire (Wanekaya et al 2006).

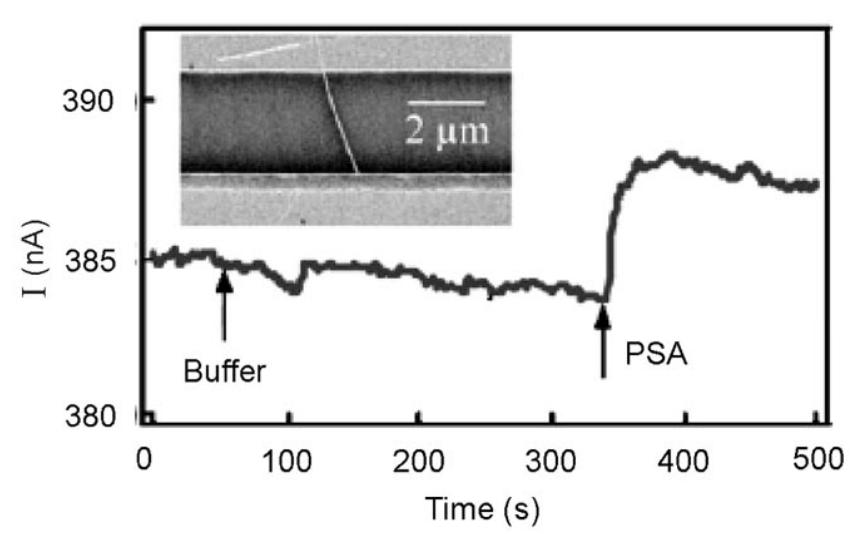

Figure 20. The curve represents the change in current as a function of time for an individual $\mathrm{In}_{2} \mathrm{O}_{3}$ nanowire when exposed to buffer and PSA. Inset: SEM image of the single $\mathrm{In}_{2} \mathrm{O}_{3}$ nanowire sensor device is shown (Wanekaya et al 2006). where the electrical current as a function of time, plotted for $\mathrm{In}_{2} \mathrm{O}_{3}$ nanowires clearly shows enhancement in current when the protein specific antigen (PSA) molecules are adsorbed on the wire surface. Considering the fact that fast and accurate detection of various biological compounds is a primary necessity for medical diagnosis, nanowire based sensors definitely hold a lot of promise in this area.

1.5a Applications: The development of nanowire based $\mathrm{pH}$ sensor (Cui et al 2001) and $\mathrm{Pb}$ nanowire based hydrogen gas sensor (Favier et al 2001) have been reported so far.

\section{Synthesis of nanowires via porous anodic aluminium oxide template}

Research works, which are focused on the realization of the potential benefits of nanowires, have incidentally led to the development of a large number of fabrication techniques. Some of the important methods are ion beam and electron beam nanolithography (Chou et al 1994; Dunn 1994; Hehn et al 1995; Cerrina and Marrian 1996; Matsui and Ochiai 1996; Gibson 1997), evaporation-condensation (Liu et al 2001), vapour-liquid-solid (VLS) growth (Wu and Yang 2000; Huang et al 2001b), hydrothermal synthesis (Gates et al 2000), and chemical synthesis (Huczko 2000). However, most of the above methods suffer from several serious limitations e.g. the conventional nanolithographic techniques are very cumbersome and require lot of efficiency and skill. Moreover, the techniques are also not suitable for large-scale production of nanowires with high aspect ratios (Das et al 1993; Sellmyer et al 2001). The hydrothermal and chemical synthesis techniques on the other hand are less attractive due to the difficulty in exercising control over the length and diameter of the nanowires during synthesis. Probably for the above reason, template based synthesis of nanowires and nanorods have recently gained lot of importance and popularity (Ozin 1992; Ying 1999).

Self-ordered nanoporous membrane of molecular sieves (Ozin 1992), track-etched polymer (Martin 1994), nanochannel array glass (Tonucci et al 1992), radiation tracketched mica (Possin 1970) and anodic aluminium oxide (AAO) (Furneaux et al 1989) are increasingly being used as the mask or the template for the nanowire fabrication. However, among the above mentioned templates AAO membrane is considered to be the most attractive due to the regular pore distribution, high pore density and high aspect ratio of pores (Routkevitch et al 1996a).

The AAO templates can be fabricated easily and during fabrication precise control can be exerted over the distribution, length and diameter of the pores. The AAO membranes are prepared by controlled electrochemical anodization, which involves oxidation of pure aluminium in an appropriate electrolyte. Anodization parameters such as anodization voltage, current, electrolyte bath temperature and 
composition are all suitably adjusted during fabrication of the template to obtain the desired distribution, size and length of the pores (Masuda et al 1997). It would be worthwhile to mention that by using different electrochemical deposition methods (Doremus et al 1958) or by other processes such as evaporation, sol-gel method (Lakshmi et al 1997), chemical vapour deposition (CVD) (Lee et al 2001), melt or solution deposition (Zhang et al 1999; Han et al 2000) and electroless deposition (Mallory and Hadju 1990; Wu and Bein 1994), nanowires of different metals and semiconductor can be fabricated in the pores of this template membrane.

Considering the importance of the above aspects in the backdrop, herein we present a detailed review on the fabrication of nanowires by using the porous anodic aluminium oxide template.

\subsection{Preparation of AAO template}

A thick porous aluminium oxide film can be produced on the pure $(99.999 \%)$ annealed aluminium by electrochemical anodization technique (Keller et al 1953). Anodization is an electrolytic oxidation process in which the metal surface, when anodic is converted primarily to an adherent oxide coating having desirable thickness and structure. Oxide layers with different morphological features can be formed by anodic oxidation of aluminium by varying the conditions during the electrochemical process, e.g. temperature, current density, voltage and duration of anodization. Therefore, we feel that it is imperative to include a brief description of the AAO template preparation.

2.1a Surface preparation prior to anodization: High purity Al foil (99.999\% purity) is used for obtaining an ordered porous oxide film on aluminium by anodization, because of the fact that the impurity atoms having different size and volume may induce internal stresses during anodization, which can lead to the formation of defective structures in porous alumina template. It is also important that the Al foil should be annealed for atleast 3-4 h at $500^{\circ} \mathrm{C}$ under nitrogen atmosphere, which helps in the removal of crystal defects and promotes grain growth. A grain size between 100 and $200 \mu \mathrm{m}$ is desirable for obtaining a uniform pore distribution during anodization (Jessensky et al 1998a).

Al foil with a thickness $>100 \mu \mathrm{m}$ is cleaned in acetone prior to anodization by ultrasonic vibration. Surface impurities are removed by immersing the cleaned $\mathrm{Al}$ foil in a solution containing $1 \% \mathrm{HF}, 10 \% \mathrm{HNO}_{3}, 20 \% \mathrm{HCl}$, and $69 \% \mathrm{H}_{2} \mathrm{O}$ by volume (Li et al 1998).

The surface roughness of the annealed Al surface is reduced to nearly $3 \mathrm{~nm}$ (Li et al 1998) by electropolishing the aluminium foil in a standard acidic electrolyte containing $165 \mathrm{ml}$ of $65 \% \mathrm{HClO}_{4}, 700 \mathrm{ml}$ of ethanol, $100 \mathrm{ml}$ of 2-butoxyethanol and $137 \mathrm{ml}$ of $\mathrm{H}_{2} \mathrm{O}$ at $50 \mathrm{~V}$ for $10 \mathrm{~s}$. 2.1b Anodization of aluminium: The electropolished Al sample is anodized in an electrochemical bath using the sample as anode plate and $\mathrm{Pt}$ mesh, graphite, $\mathrm{Al}$ or stainless steel as the cathode. Aqueous sulfuric, oxalic or phosphoric acid is used as an electrolyte (Diggle et al 1969; Despic and Parkhuitik 1989). During anodization, a thick porous alumina layer gradually grows over a very thin dense barrier oxide layer, which acts as an interface between the pure Al surface and porous alumina oxide layer. Here it is to be noted that pure $\mathrm{Al}$ and few other metals like $\mathrm{Nb}, \mathrm{W}$, $\mathrm{Zr}$ etc which are prone to oxidation under ambient condition develops a thin amorphous, insulating and inert oxide layer on the metal surface commonly known as the barrier oxide layer. The average thickness of this barrier layer ranges between 150 and $180 \AA$ (Martin 1996).

It is also worthwhile to mention that for the preparation of ideally ordered porous structure the process parameters such as anodization voltage, anodization current, electrochemical bath temperature, type and concentration of electrolyte should be critically maintained.

Different types of electrolytic baths are used for the anodization. Some examples are: anodization using $0 \cdot 3 \mathrm{M}$ $(\mathrm{COOH})_{2}$ solution at $1^{\circ} \mathrm{C}$ for $2-4 \mathrm{~h}$ with an anodization voltage between 30 and $40 \mathrm{~V}$ (Masuda and Fukuda 1995). Anodization can also be carried out by using $20 \mathrm{wt} \%$ (2 M) $\mathrm{H}_{2} \mathrm{SO}_{4}$ at $1{ }^{\circ} \mathrm{C}$ with an applied voltage of $19 \mathrm{~V}$ for $1-2$ days (Habib 2001) or $1 \mathrm{M} \mathrm{H}_{3} \mathrm{PO}_{4}$ under an applied voltage of $160 \mathrm{~V}$ for more than one day at low temperature in the range $1-10^{\circ} \mathrm{C}$ (Bocchetta et al 2003).

The pore diameter, cell dimension, pore distribution etc strongly depend on the applied voltage. In the anodization process the role of the anodization current is also considered to be very important. The current densities during the porous oxide film growth using $15 \% \mathrm{wt} / \mathrm{vol}$. $\mathrm{H}_{2} \mathrm{SO}_{4}$ with bath temperatures of $20^{\circ} \mathrm{C}, 25^{\circ} \mathrm{C}$ and $30^{\circ} \mathrm{C}$ are 5,15 and $35 \mathrm{~mA} / \mathrm{cm}^{2}$, respectively (Patermarakis and Papandreadis 1993). Since the conductivity and $\mathrm{pH}$ values of different electrolytes are different and are influenced by the concentration, ranges of anodization voltage are also different for different electrolytes. However, in all the cases the anodization temperature is purposely kept low, preferably below the room temperature because, high bath temperature enhances the dissolution of porous oxide film in the electrolyte.

Masuda and Satoh (1996) reported that rather than onetime (single step) anodization, two-step anodization is helpful in producing the ideally ordered porous structure. In the first step, Al is oxidized in $0.3 \mathrm{M}$ oxalic acid at $40 \mathrm{~V}$ at low temperature, below room temperature for $15 \mathrm{~min}$. The porous oxide layer so formed over the Al sample is removed by chemical etching in a mixture of $0.2 \mathrm{M}$ chromic acid and $0.4 \mathrm{M}$ phosphoric acid at a bath temperature of $60^{\circ} \mathrm{C}$ (Sellmyer et al 2001). Removal of the porous film from the Al sample leaves behind an ordered concave textured structure on the sample surface. This 'textured' $\mathrm{Al}$ is again anodized in the same electrolyte for a day or 
more. During this second step anodization process, the concave textured pattern on the aluminium sample surface acts as the sites for deep pore growth and is helpful in growing the porous oxide film uniformly (Masuda et al 1997).

A pre-textured Al sample can also be used to fabricate uniformly ordered alumina oxide film (Masuda et al 1997) by anodization. In this method, a hexagonally ordered convex pattern is produced on the hard $\mathrm{SiC}$ using electron beam lithography technique. This patterned $\mathrm{SiC}$ is used as the master mould. This SiC mould is indented into the $\mathrm{Al}$ sample surface at high pressure $\left(\sim 2800 \mathrm{~kg} / \mathrm{cm}^{2}\right)$ before anodization is carried out. This process helps to get an ideally distributed shallow order concave pattern on the Al sample surface (Asoh et al 2001). When the sample is anodized, the shallow ordered concave patterns act as the site for deep pore growth with uniform, similar morphological and geometrical features.

2.1c Mechanism of pore growth and reactions: During the anodization process a constant voltage is applied between the electrodes. Therefore, the applied electric field lines lie perpendicular to the sample surface (anode) towards the cathode. This applied electric field increases the dissolution of the barrier oxide layer and thus favours pore growth. Due to the competition that prevails among the growing pores, few of them stop growing while others grow. The pores grow perpendicular to the surface when the field-enhanced dissolution of the oxide at the electrolyte/ oxide interface is equilibrated with the growth of oxide that occurs at the oxide/metal interface. Oxidation occurs at the metal/oxide interface by the migration of oxygen containing ions $\left(\mathrm{O}^{2-}\right.$ or $\left.\mathrm{OH}^{-}\right)$from the electrolyte by the following reaction (Uchi et al 2001)

$$
2 \mathrm{Al}+3 \mathrm{O}^{2-} \rightarrow \mathrm{Al}_{2} \mathrm{O}_{3}+6 e^{-} .
$$

Dissolution of the oxide layer is caused mainly by the hydration reaction of the formed oxide layer as shown below (Alwitt and Takei 1983; Xu et al 1985; Shimizu et al 1992)

$$
2 \mathrm{Al}^{3+}+3 \mathrm{H}_{2} \mathrm{O} \rightarrow \mathrm{Al}_{2} \mathrm{O}_{3}+6 \mathrm{H}^{+} .
$$

It is to be noted that under the applied electric field the $\mathrm{Al}^{3+}$ ions migrate through the barrier oxide layer. This electric field also helps in the transport of the oxygen containing ions $\left(\mathrm{O}^{2-}\right.$ or $\left.\mathrm{OH}^{-}\right)$from the electrolyte into the barrier oxide layer towards the Al substrate. The schematic representation of the ionic migration at the pore bottom under the applied electric field is given in figure 21 . The electrons ejected into the electrolyte and combined with hydrogen ions to generate hydrogen gas at cathode (Thompson and Wood 1983).

Barrier oxide growth without pore formation occurs when the $\mathrm{Al}^{3+}$ ions reach the electrolyte/oxide interface and contribute to the oxide formation. Porous alumina oxide layer formed when the $\mathrm{Al}^{3+}$ ions drift through the oxide layer and are ejected into the solution at the oxide/electrolyte interface (Shimizu et al 1992)

$$
2 \mathrm{Al} \rightarrow 2 \mathrm{Al}^{3+}+6 e^{-} .
$$

Loss of $\mathrm{Al}^{3+}$ ions in the electrolyte has been found to be a prerequisite for porous oxide growth. Thus at steady state pore grows perpendicular to the Al surface when an equilibrium is established between the field enhanced dissolution of oxide layer at oxide/electrolyte interface and the oxide growth at metal/oxide interface (O'Sullivan and Wood 1970; Parkhutik and Shershulsky 1992).

During the anodization of aluminium, the porous layer formed is assumed to be of $\mathrm{Al}_{2} \mathrm{O}_{3}$. The atomic density of aluminium in $\mathrm{Al}_{2} \mathrm{O}_{3}$ is lower than that of metallic aluminium by a factor of two. The volume expansion of $\mathrm{Al}_{2} \mathrm{O}_{3}$ will be nearly twice that of the original aluminium metal. This volume expansion takes place at the metal/oxide interface leading to a compressive stress during oxide formation. This stress is the origin of the repulsive forces that appear between the neighbouring pores (Jessensky et al 1998b) and it is believed that volume expansion in the vertical direction pushes the pore wall upward.

2.1d Morphology and geometrical structure of porous aluminium oxide: Atomic force microscopic (AFM) techniques are commonly used to show the three-dimensional surface topology of the porous film and scanning tunneling microscopic (STM) image gives an idea about the geometrical structure in real space. It has been found that depending on certain sets of parameters e.g. composition of the electrolyte, applied voltage etc, the pore diameter ranges from $4-200 \mathrm{~nm}$, pore length from $1-50 \mu \mathrm{m}$ and pore density in the range of $10^{9}-10^{11} / \mathrm{cm}^{2}$ (Routkevitch et al 1996a).

It has been seen that the porous anodic alumina produced during anodization, have hexagonal closed packed

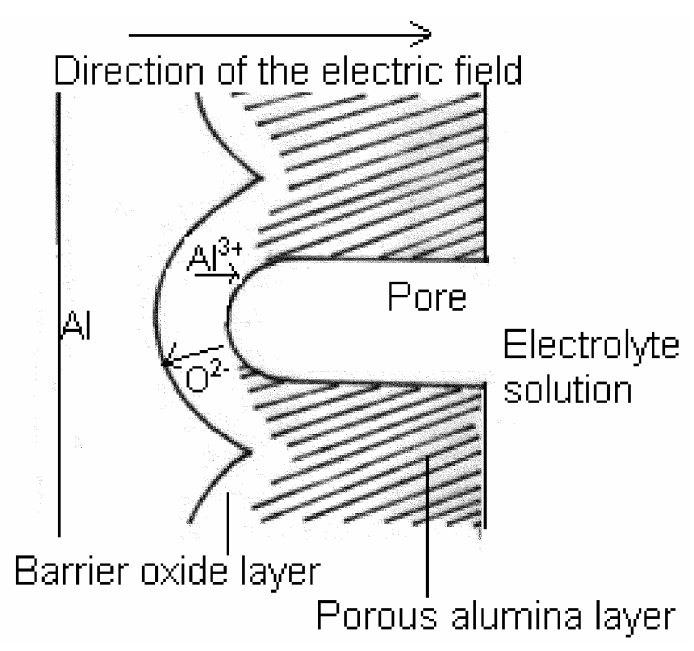

Figure 21. Schematic showing the ionic migration under applied electric field. 
nearly honeycomb like structure as shown in figure 22 . The pores appear nearly at the centre of each hexagonal columnar cell. The channel like pores lie perpendicular to the aluminium sample surface (Jessensky et al 1998b). However, the geometry of AAO film usually obtained by anodization process is far from that of the idealized model as the arrangement of the cells is not perfectly hexagonal (see figure 23) (O'Sullivan and Wood 1970).

\subsection{Fabrication of nanowires by pore filling through electro-deposition technique}

Methods that involve direct pore filling of the AAO template are considered to be straightforward and versatile

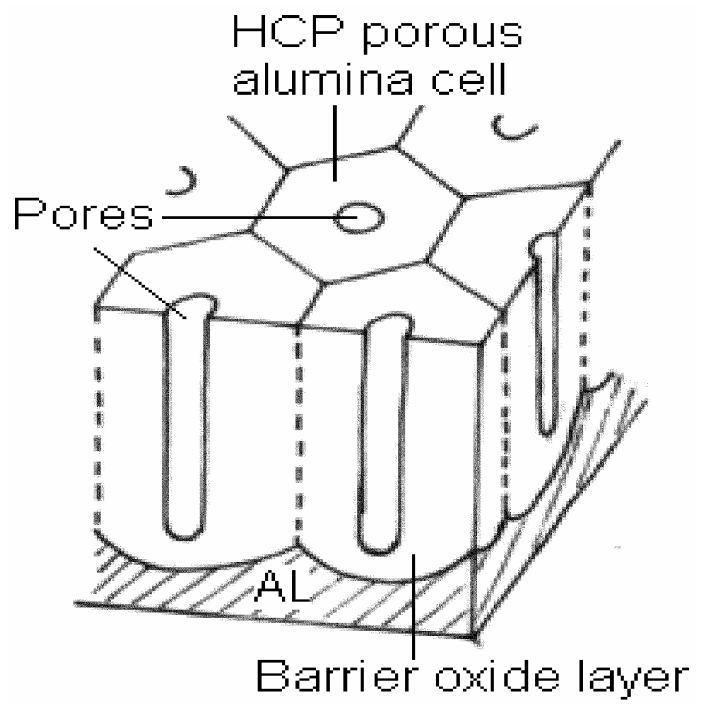

Figure 22. Schematic diagram showing the honeycomb like porous alumina structure.

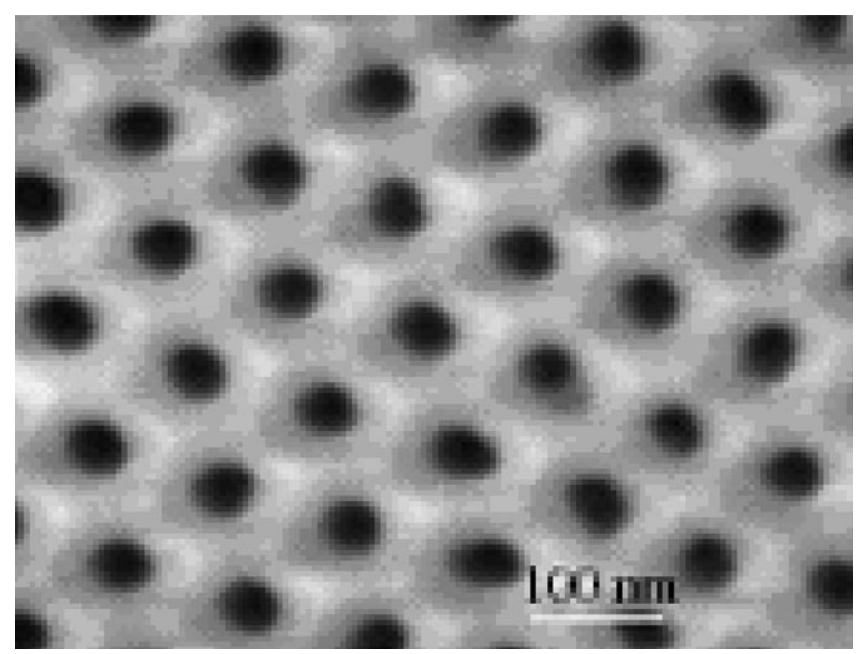

Figure 23. SEM image of the top surface of AAO membrane (Heremans et al 1998). techniques for synthesizing nanowires. Highlights of some of the AAO pore filling techniques that have gained reasonable popularity are described below.

2.2a Pressure injection: In this technique low melting point metals and semiconductors are melted and injected into the pores of AAO template by applying high pressure. The material that has infiltrated into the pores is allowed to solidify and form nanowires. The nanowires were finally extracted by dissolving the alumina template chemically. Nanowires of $\mathrm{Bi}, \mathrm{Sn}, \mathrm{In}, \mathrm{Al}, \mathrm{Te}, \mathrm{Se}, \mathrm{GaSb}$ and $\mathrm{Bi}_{2} \mathrm{Te}_{3}$ have been reportedly fabricated by this technique (Huber et al 1994; Zhang et al 1998b).

2.2b Vapour deposition: Physical and chemical vapour deposition techniques are often employed for pore filling and fabricating nanowires. Bi nanowires in AAO template have been synthesized by introducing $B i$ vapour into the pores of the AAO template, which is then solidified by cooling (Heremans et al 2000). Compound semiconductor nanowires of $\mathrm{GaN}$ have also been reportedly synthesized in AAO template by gas phase reaction between $\mathrm{Ga}_{2} \mathrm{O}$ vapour and ammonia (Cheng et al 1999).

2.2c Vapour-liquid-solid (VLS) method: This method involves absorption of source material from the gaseous phase into a liquid droplet that acts as a catalyst. Primarily a liquid alloy is formed which becomes supersaturated and precipitates out the source material by nucleation. The precipitate acts as a preferred site for further deposition and growth of the material at the interface of the liquid droplet, favouring growth of the precipitate into a nanowire by suppressing further nucleation on the same catalyst. It has been shown that the diameter of the nanowire depends on the diameter of the liquid alloy droplet. Recently, porous alumina membrane has been used as an alternative to control nanowire diameter in the VLS process (Lew et al 2002; Bogart et al 2005). Defect free Si nanowires with diameters in the range of $4-5 \mathrm{~nm}$ and lengths of several microns were synthesized by using a supercritical fluid solution phase approach where alkanethiol coated Au nanocrystal ( $2.5 \mathrm{~nm}$ in diameter) were used as seeds to direct the one dimensional crystallization of $\mathrm{Si}$ in a solvent heated and pressurized above its critical point (Holmes et al 2000). The reaction pressure controls the orientation of the nanowires.

2.2d Pulsed laser deposition: Recently, pulsed laser deposition (PLD) technique is being used to deposit materials on top of the porous AAO template. The material deposited inside the pores is shaped into nanowires and the material that is deposited in the nonporous region that separate adjacent pores, assume different morphologies depending on the nature of the surface. It has been reported that ordered arrays of $\mathrm{ZnO}$ nanodots with an average diameter of $60 \mathrm{~nm}$ and a periodicity of $100 \mathrm{~nm}$ were 
fabricated by PLD using AAO template. Controlling the oxygen pressure used in PLD photoluminescence (PL) at $380 \mathrm{~nm}$ is observed from the $\mathrm{ZnO}$ nanodots (Bae et al 2006).

2.2e Chemical conversion: Synthesis of nanowires by chemical reaction in the pores of AAO template is another important approach. Initially nanowires of the constituent element is prepared, which is then reacted with chemicals containing the desired element to form the final product. $\mathrm{Ag}_{2} \mathrm{Se}$ nanowires were synthesized by reacting crystalline Se nanowires with aqueous $\mathrm{AgNO}_{3}$ at room temperature (Ma et al 2002).

$\mathrm{ZnO}$ nanowires were prepared by oxidizing metallic zinc nanowires that were prepared by electrodeposition in the pores of AAO template prior to their oxidation in air at $300^{\circ} \mathrm{C}$ for $35 \mathrm{~h}$. The free standing $\mathrm{ZnO}$ nanowires were extracted from the template by selective dissolutions ( $\mathrm{Li}$ et al 2000).

Hollow nanotubes of $\mathrm{MoS}_{2} \sim 30 \mathrm{~nm}$ long with $50 \mathrm{~nm}$ external diameters were prepared by filling the pores of the AAO template with a mixture of molecular precursors, $\left(\mathrm{NH}_{4}\right)_{2} \mathrm{MoS}_{4}$ and $\left(\mathrm{NH}_{4}\right)_{2} \mathrm{Mo}_{3} \mathrm{~S}_{13}$. The filled template was then heated at an elevated temperature to thermally decompose the precursor into $\mathrm{MoS}_{2}$ (Zelenski and Dorhout 1998).

2.2f Colloidal dispersion filling: Oxide nanowires, nanorods and nanotubes can be synthesized easily by filling the template with colloidal dispersions. The colloidal dispersion was generally prepared through the sol-gel technique. The porous template was placed in a stable sol for appropriate length of time to drive the sol into the pores by capillary force. The filled template is then withdrawn from the sol and dried prior to firing for densification of the sol-gel derived nanowires, nanorods or nanotubes (Lakshmi et al 1997).

$2.2 \mathrm{~g}$ Electro-deposition method: Inspite of the fact that all the above mentioned techniques are advantageously used for the deposition of nanostructure materials (NSMs) into the pores of the nanoporous membrane, electrodeposition or electrochemical deposition is regarded as one of the most popular methods of pore filling with conducting metals to obtain continuous arrays of nanowires with large aspect ratios (Huixin and Nongjian 2003). Electrochemical deposition route is easy, low-cost as well as less skill dependent compared to other techniques mentioned above. Structural analysis shows that the electrodeposited nanowires tend to be densely packed, continuous and highly crystalline. Moreover, by simply monitoring the total amount of passing charge one can precisely control the aspect ratios of the metal nanowires.

$2.2 \mathrm{~g}(\mathrm{i})$ Electro-deposition bath set up: In the electrodeposition method the electrochemical bath set up is simi- lar to that used for the electro-plating process. The porous alumina membrane with natural aluminium-substrate support is used as the electrode. Sometimes the anodic alumina oxide (AAO) membrane is separated out from the Al-substrate and a thin metal film of $\mathrm{Ag}$ or $\mathrm{Au}$ is deposited in the membrane by evaporation technique (Mikhaylova et al 2002). This thin metal film supported membrane acts as the active electrode. The appropriate metal salt solution, containing the metal ions is used as the electrolyte in the electro-deposition process.

2.2g(ii) Electro-deposition method: The thin barrier oxide layer underneath the pores of AAO membrane has high resistivity $\left(10^{10}-10^{12} \Omega \mathrm{cm}\right.$ ) (Linden et al 1990). A.C. electrodeposition technique is preferred because direct current cannot pass through the barrier oxide layer (Lee et al 2002; Zeng et al 2002). Electro-deposition depends on different process parameters such as deposition current amplitude, frequency of current (voltage), electrochemical bath temperature and $\mathrm{pH}$ value of the electrolyte (Rahman et al 2003). In a.c. electrodeposition the anodic alumina template acts like a 'rectifier' when alternating current (voltage) is applied between the template and other electrodes. The ionic conduction starts when the template electrode acts as a cathode (during cathodic half cycle). Under this condition the cations from the electrolyte layer that remain attached to the template electrode diffuse to the pore bottom and are electrodeposited. On the other hand, while the template becomes anodic (during anodic half cycle), ionic conduction is cut off and the material deposited in the pore bottom of the membrane is not re-anodized. Here, it is to be noted that during the cathodic half cycle the electrolyte layer, which is attached to the template electrode becomes depleted of cation, as the ion diffusion from the rest of the electrolyte to this thin attached layer is very slow. Therefore, the anodic half cycle is helpful in the sense that during this interval or period cations get the time to diffuse into the thin electrolyte layer, from rest of the electrolyte solution making electro-deposition possible during the next cathodic half cycle.

Here, it would be worthwhile to mention that d.c. pulsed electro-deposition can also be used for pore filling, however, this process has the ability to fill-up only $10-20 \%$ of the pores of the membrane (Prieto et al 2001). On the other hand, a.c. electro-deposition is capable of high pore filling ratio (Nielsch et al 2000; Sauer et al 2002; Seadi and Ghorbani 2005).

2.2g(iii) Electro-deposition of nanowires: Metallic nanowires of $\mathrm{Cu}$ (Blondel et al 1994; Piraux et al 1994), Ag (Bhattacharrya et al 2000; Sauer et al 2002), Bi (Liu et al 1998; Piraux et al 1999), Au (Hornyak et al 1997; Zhang et al 2001) and different transition metals such as Fe (Al Mawlawi et al 1991; Peng et al 2000), Co (Ferré et al 1997; Zeng et al 2000), Ni (Ferré et al 1997; Sun et al 
1999) and their alloys can be fabricated by the electrodeposition method by filling the pores of the alumina template. Nanowires of different semiconductors, superlattice and superconductors such as $\mathrm{Pb}$ (Yi and Schwarzacher 1999) can also be fabricated. Representative SEM image of silver nanowires fabricated in alumina template by electrodeposition is shown in figure 24 (Riveros et al 2006).

It has been reported that $\mathrm{Fe}$ nanowires are deposited into the pores of the template by using a.c. pulse. The electrolyte solution contains $120 \mathrm{~g} / \mathrm{l}$ of $\mathrm{FeSO}_{4} \cdot 7 \mathrm{H}_{2} \mathrm{O}$; $45 \mathrm{~g} / 1$ of $\mathrm{H}_{3} \mathrm{PO}_{3} ; 1 \mathrm{~g} / 1$ of ascorbic acid and $2 \mathrm{ml} / 1$ of glycerin. The $\mathrm{pH}$ value of the solution was maintained at $\approx 3$ throughout the electrodeposition process (Hickmott 2000). Similarly, Co nanowires were fabricated from $\mathrm{CoSO}_{4}$ salt solution containing $400 \mathrm{~g} / \mathrm{l}$ of $\mathrm{CoSO}_{4} \cdot 7 \mathrm{H}_{2} \mathrm{O}$ and $40 \mathrm{~g} / \mathrm{l}$ of $\mathrm{H}_{3} \mathrm{BO}_{4}$ as electrolyte (Mikhaylova et al 2002). In both the $\mathrm{Fe}$ and $\mathrm{Co}$ electro-deposition processes, a.c. voltage pulse of $10-20 \mathrm{~V}$ with frequency ranging from 50-300 Hz was used (Menon et al 2000). It has also been reported that by using highly concentrated electrolyte like $300 \mathrm{~g} / 1 \mathrm{NiSO}_{4} \cdot 6 \mathrm{H}_{2} \mathrm{O}$ or $45 \mathrm{~g} / 1 \mathrm{NiCl}_{2} \cdot 6 \mathrm{H}_{2} \mathrm{O}$ and $45 \mathrm{~g}$ of $\mathrm{H}_{3} \mathrm{BO}_{4}$ solution of $\mathrm{pH} 4.5$ (Nielsch et al 2001), Ni nanowires can be deposited into the pores of the alumina template under a negative current pulse of $-25 \mathrm{~mA} / \mathrm{cm}^{2}$ for a duration of $6 \mathrm{~ms}$ followed by a positive voltage pulse of $+4 \mathrm{~V}$ for $2 \mathrm{~ms}$ only (Nielsch et al 2001). Semiconductor nanowires of CdS (Routkevitch et al 1996b) have been fabricated by electrodeposition method using the alumina oxide template. It has been reported (Xu D et al 2000; Xu D S et al 2000) that single crystal compound semiconductor

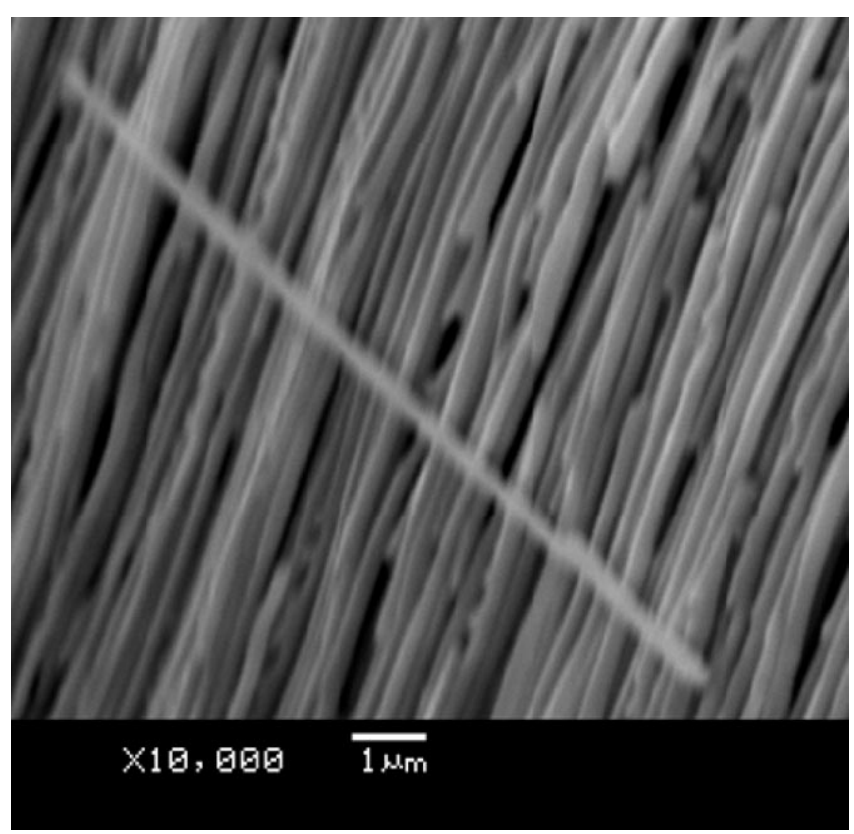

Figure 24. SEM image of $\mathrm{Ag}$ nanowires separated from the alumina template (Riveros et al 2006). nanowires of $\mathrm{CdS}, \mathrm{CdSe}$ and $\mathrm{CdTe}$ can also be fabricated into the porous alumina template by electrodeposition.

Xu D et al (2000) and Xu D S et al (2000) reported that $\mathrm{Co}-\mathrm{Cu}$ superlattice nanowires can also be synthesized by varying the cathodic potential in the electrolyte solution containing two different metal ions. These nanowires contain periodic modulation of composition along the wire axes. Here it would be worthwhile to mention that after pore filling with required materials, the aluminium substrate was removed by $\mathrm{HgCl}_{2}$ solution (Terry et al 2003). The periodic arrays of nanowires may be separated out of the template by dissolving AAO membrane in hot $6 \mathrm{M}$ $\mathrm{NaOH}$ solution (Terry et al 2003).

\section{Conclusions}

In the present review article, physical properties of the nanowires along with their potential applications are described in detail. It is concluded that (i) nanowires possess physical and chemical properties that are unique and often conspicuously different from their bulk parent counterparts and (ii) nanowires are potential candidates for different nanoscale electrical, thermoelectrical, optical, magnetic, bio-medical and sensor device applications.

The review has also established that synthesis of nanowires via AAO template is very attractive due to the uniform pore morphology and high pore density. Moreover, the technique is reliable, simple and economical.

\section{Acknowledgements}

Authors are thankful to the Department of Science and Technology, New Delhi, for providing financial support through the fast track scheme (ref no-SR/FTP/CS-8/2004) for the work. The authors are also thankful to Nature Publishing Group, Wiley-VCH, IOP Publishing Limited, American Institute of Physics and Royal Society of Chemistry for their permission to use some of the published figures in this review.

\section{References}

Aldén M, Skriver H L, Mirbt S and Johansson B 1994 Surf. Sci. 315157

Al Mawlawi D, Coombs N and Moskovits M $1991 \mathrm{~J}$. Appl. Phys. 704421

Alwitt R S and Takei H 1983 Thin Films Sci. \& Technol. 4741

Asoh H, Nishio K, Nakao M, Tamamura T and Masudaa H 2001 J. Electrochem. Soc. 148 B152

Aspnes D E 1982 Thin Solid Films 89249

Au F C K, Wong K W, Tang Y H, Zhang Y F, Bello I and Lee S T 1999 Appl. Phys. Lett. 751700

Bae C H, Park S M, Park S C and Ha J S 2006 Nanotechnology 17381 
Beck G, Petrikowski K and Khan H R 2005 Conf. on microstructure analysis in materials science (TU Bergakademie Freiberg: Leitung und Zentrales Tagungsbüro)

Beutler D E and Giordano N 1988 Phys. Rev. B38 8

Bhattacharrya S, Saha S K and Chakravorty D 2000 Appl. Phys. Lett. 763896

Bhushan B (ed.) 2005 Springer handbook of nanotechnology (Berlin, Heidelberg: Springer)

Björk M T, Ohlsson B J, Thelander C, Persson A I, Deppert K, Wallenberg L R and Samuelson L 2002a Appl. Phys. Lett. 81 4458

Björk M T, Ohlsson B J, Sass T, Persson A I, Thelander C, Magnusson M H, Deppert K, Wallenberg L R and Samuelson L 2002b Nano. Lett. 287

Black M R, Lin Y M, Cronin S B, Rabin O and Dresselhaus M S 2002 Phys. Rev. B65 195417

Blom S, Gorelik L Y, Jonson M, Shekhter R I, Scherbakov A G, Bogachek E N and Landman U 1998 Phys. Rev. B58 16305

Blondel A, Meier J P, Doudin B and Ansermet J P 1994 Appl. Phys. Lett. 653019

Bocchetta P, Sunseri C, Masi R, Piazza S and Quarto F D 2003 Mater. Sci. \& Eng. C23 1021

Bogart T E, Dey S, Lew K -K, Mohney S E and Redwing J M 2005 Adv. Mater. 17114

Bohreu C F and Huffman D R 1983 Absorption and scattering of light by small particle (New York: Wiley)

Cardona M 1982 Light scattering in solids (Berlin, Heidelberg: Springer)

Cerrina F and Marrian C 1996 MRS Bull. 2156

Chatterjee K, Basu S and Chakravorty D 2006 Mater. Res. Soc. 2134

Chen G, Dresselhaus M S, Dresselhaus G, Fluerial J P and Caillat T 2003 Int. Mater. Rev. 4845

Cheng G S, Zhang L D, Zhu Y, Fei G T, Li L, Mo C M and Mao Y Q 1999 Appl. Phys. Lett. 752455

Chien C L 1991 J. Appl. Phys. 695267

Chou S Y, Wei M, Krauss R P and Fisher B P 1994 J. Vac. Sci. Technol. B12 3695

Chung S W, Yu J Y and Heath J R 2000 Appl. Phys. Lett. 76 2068

Costa-Krämer J L, Garcia N and Olin H 1997 Phys. Rev. Lett. 784990

Cui Y, Duan X, Hu J and Lieber C M 2000 J. Phys. Chem. B104 5213

Cui Y, Wei Q, Park H and Lieber C 2001 Science 2931289

Dames C and Chen G 2002 21st Int. conf. thermoelectrics: Proc. ICT symposium, Long Beach (Piscataway: IEEE) pp $317-320$

Das B, Subramanium S and Melloch M R 1993 Semicond. Sci. Technol. 81347

Derycke V, Martel R, Appenzeller J and Avouris P 2001 Nano Letts 1453

Despic A and Parkhuitik V P 1989 Modern aspects of electrochemistry (New York: Plenum) Vol. 20

Diggle J W, Downie T C and Goulding C W 1969 Chem. Rev. 69 365

Ding M, Kim H and Akinwande A I 1999 Appl. Phys. Lett. 75 823

Doremus R H, Roberts B W and Turnbull D 1958 Growth and perfection of crystal (New York: John Wiley) p. 13
Dresselhaus G, Dresselhaus M S, Zhang Z, Sun X, Ying J and Chen G 1998 17th Int. conf. thermoelectrics: Proc. ICT'98, Nagoya (ed.) K Koumoto (Piscataway: Institute of Electrical and Electronics Engineers Inc) pp 43-46

Duan X, Huang Y, Cui Y, Wang J and Lieber C M 2001 Nature 40966

Duan X, Huang Y and Lieber C M 2002 Nano. Lett. 2487

Dunn P N 1994 Solid State Technol. 37 49, 52, 58, 61

Favier F, Walter E C, Zach M P, Benter T and Penner R M 2001 Science 2932227

Ferré R, Ounadjela K, George J M, Piraux L and Dubois S 1997 Phys. Rev. B56 14066

Foss C A, Hornyak G L, Stocket J A and Martin C R 1994 J. Phys. Chem. 982963

Furneaux R C, Rigby W R and Davidson A P 1989 Nature 337 147

Garnett J C M 1906 Philos. Trans. R. Soc. London A205 237

Gates B, Yin Y and Xia Y 2000 J. Am. Chem. Soc. 12212582

Gibson J M 1997 Phys. Today 56

Gudiksen M S, Lauhon L J, Wang J, Smith D C and Lieber C M 2002 Nature 415617

Habib K 2001 Corros. Sci. 43449

Han Y J, Kim J M and Stucky G D 2000 Chem. Mater. 122068

Hasegawa H 2001 ECS 2001 joint international meeting, 6th International symposium on quantum confinement (San Francisco, California: The International Society of Electrochemistry)

Hehn M, Ounadjela K, Bucher J, Rousseaux F, Deeanini D, Bartenlian B and Chappert C 1995 Science 2721782

Heremans J and Thrush C M 1999 Phys. Rev. B59 12579

Heremans J, Thrush C M, Zhang Z, Sun X, Dresselhaus M S, Ying J Y and Morelli D T 1998 Phys. Rev. B58 R10091

Heremans J, Thrush C M, Lin Y M, Cronin S, Zhang Z, Dresselhaus M S and Mansfield J F 2000 Phys. Rev. B61 2921

Heremans J, Thrush C M, Morelli D T and Wu M C 2002 Phys. Rev. Lett. 88216801

Hickmott T W 2000 J. Appl. Phys. 8711

Hicks L D and Dresselhaus M S 1993 Phys. Rev. B47 16631

Holmes J D, Johnston K P, Doty R C and Korgil B A 2000 Science 2871471

Hornyak G L, Patrissi C J and Martin C M 1997 J. Phys. Chem. B101 1548

Huang H H, Ni X P, Loy G L, Chew C H, Tan K L, Loh F C, Deng J F and Xu G Q 1996 Langmuir 12909

Huang M H et al 2001a Science 2921897

Huang M H et al 2001b Adv. Mater. 13113

Huang Y, Duan X, Cui Y, Lauhon L J, Kim K H and Lieber C 2001 Science 2941313

Huang Y, Duan X, Cui Y and Lieber C M 2002 Nano. Lett. 2 101

Huang Y, Duan X and Lieber C M 2005 Wiley-VCH Verlag GmbH \& Co. KGaA, D-69451 Weinheim

Huber C A, Huber T E, Sadoqi M, Lubin J A, Manalis S and Prater C B 1994 Science $\mathbf{2 6 3} 800$

Huczko A 2000 Appl. Phys. A70 365

Huixin H and Nongjian J T 2003 Encyclopedia of nanoscience and nanotechnology (ed.) H S Nalwa (Valencia, California, USA: American Scientific Publishers) Vol. 10, pp 1-18

Huynh W U, Dittmer J J and Alivisatos A P 2002 Science 295 2425

Jessensky O, Muller F and Gosele U 1998a Appl. Phys. Lett. 72 1173 
Jessensky O, Muller F and Gosele U 1998b J. Electrochem. Soc. 1453735

Jiang X, Xie Y, Lu J, Zhu L, He W and Qian Y 2001 J. Mater. Chem. 111775

Johnson J C, Yan H, Schaller R D, Haber L H, Saykally R J and Yang P 2001 J. Phys. Chem. B105 11387

Johnson J C, Choi H J, Knutsen K P, Schaller R D, Yang P and Saykally R J 2002 Nature Mater. 1106

Keller F, Hunter M S and Robinson D L 1953 J. Electrochem. Soc. $\mathbf{1 0 0} 411$

Kerker M 1969 Scattering of light and other electromagnetic radiation (New York: Academic Press)

Kim J R, Oh H, So H M, Kim J J, Kim J, Lee C J and Lyu S C 2002 Nanotechnology 13701

Lakshmi B B, Dorhout P R and Martin C R 1997 Chem. Mater. 9857

Lauhonn L J, Gudiksen M S, Wang D and Lieber C M 2002 Nature $\mathbf{4 2 0} 57$

Lee K B, Lee S M and Cheon J 2001 Adv. Mater. 13517

Lee K H, Lee H Y, Jeung W Y and Lee W Y 2002 J. Appl. Phys. 918513

Lee M W, Twu H Z, Chen C C and Chen C H 2001 Appl. Phys. Lett. 793693

Lew K -K, Reuther C, Carim A H and Recluring J M $2002 \mathrm{~J}$. Vac. Sci. Technol. B20 389

Li A P, Muller F, Birner A, Nielseh K and Gosele U 1998 J. Appl. Phys. 846023

Li Y, Cheng G S and Zhang L D 2000 J. Mater. Res. 152305

Lin Y M and Dresselhaus M S 2002 MRS symp. proc. Boston (eds) J M Buriak et al (Boston: Materials Research Society Press) 737 p. F8.18

Lin Y M and Dresselhaus M S 2003 Phys. Rev. B68 075304

Lin Y M, Sun X and Dresselhaus M S 2000 Phys. Rev. B62 4610

Lin Y M, Rabin O, Cronin S B, Ying J Y and Dresselhaus M S 2002 Appl. Phys. Lett. 812403

Linden B V, Terryn H and Vereehen J 1990 J. Appl. Electrochem. 20798

Liu F, Press M R, Khanna S N and Jana P 1989 Phys. Rev. B39 6914

Liu K, Chien C L, Searson P C and Kui Y Z 1998 Appl. Phys. Lett. 731436

Liu Y, Zheng C, Wang W, Yin C and Wong G 2001 Adv. Mater. 131883

Lyons D M, Ryan K M, Morris M A and Holmes J D 2002 Nano. Lett. 2811

Ma X D, Qian X F, Yin Z and Zhu Z K 2002 J. Mater. Chem. 12663

Maier S A, Kik P G and Atwater H A 2002 Appl. Phys. Lett. 81 1714

Maier S A et al 2003 Nature Mater. 2229

Mallory G O and Hadju J B 1990 Electroless plating: Fundamentals and applications (Orlando, FL: American Electroplates and Surface Finishing Society)

Martin C R 1994 Science 2661961

Martin C H 1996 Chem. Mater. 81739

Masuda H and Fukuda K 1995 Science 2681466

Masuda H and Satoh M 1996 Jap. J. Appl. Phys. L126 1135

Masuda H, Hasegawa F and Ono S 1997 J. Electrochem. Soc. $144 \mathrm{~L} 127$

Masuda H, Yamada H, Satoh M, Asoh H, Nakao M and Tamamura T 1997 Appl. Phys. Lett. 7119
Matsui S and Ochiai Y 1996 Nanotechnology 7247

Melle S, Menéndez J L, Armelles G, Navas D, Vázquez M, Nielsch K, Wehrspohn R B and Gosele U 2003 Appl. Phys. Lett. 2283

Menon L, Zeng M, Zeng H, Bandyopadhyay S and Sellmyer D J 2000 J. Electron. Mater. 29510

Mikhaylova M, Toprak M, Kim D K, Zhang Y and Muhammed M 2002 Mater. Res. Soc. Symp. Proc. 704 W6.34.1

Molaresa M E et al 2003 Appl. Phys. Lett. 8213

Muller C J, van Ruitenbeek J M and de Jongh L J 1992 Phys. Rev. Lett. 69140

Muller C J, Krans J M, Todorov T N and Reed M A 1996 Phys. Rev. B53 1022

Nicewarner Pena S R et al 2004 Encyclopedia of nanoscience and nanotechnology (Valencia, California, USA: American Scientific Publishers) Vol. 6, p. 215

Nielsch K, Muller F, Li A P and Gosele U 2000 Adv. Mater. 12 582

Nielsch K, Wehrspohn R B, Fischer S F, Kronmiller H, Kirsehner J and Gosele U 2001 Mater. Res. Soc. Symp. Proc. 9636

O'Sullivan J P and Wood G C 1970 Proc. R. Soc. London A317 511

Ozin G A 1992 Adv. Mater. 4612

Parkhutik V P and Shershulsky V I 1992 J. Phys. D: Appl. Phys. 251258

Patermarakis G and Papandreadis N 1993 Electrochim. Acta 38 1413

Peng Y, Zhang H L, Pan S L and Li H L 2000 J. Appl. Phys. 87 7405

Peng Y, Shen T H and Ashworth B 2003 J. Appl. Phys. 937050

Pierce J P, Plummer E W and Shen E 2002 Appl. Phys. Lett. 81 1890

Piraux L, George J M, Despres J F, Leroy C, Ferain E, Legras R, Ounadjela K and Fert A 1994 Appl. Phys. Lett. 652484

Piraux L, Dubois S, Duvail J L, Radulescu A, DemoustierChampagne S, Ferain E and Legras R 1999 J. Mater. Res. 14 3042

Possin G E 1970 Rev. Sci. Instrum. 41772

Prieto A L, Sander M S, Martin-Gonzalez M S, Gronsky R, Sands T and Stacy A M 2001 J. Am. Chem. Soc. 1237160

Rahman I Z, Razeeb K M, Rhaman M A and Kamruzzaman Md 2003 J. Magn. \& Magn. Mater. 262166

Ratner M and Ratner D 2003 Nanotechnology: A gentle introduction to the next big idea (London: Pearson Education publication)

Redwing J, Mayer T, Mohney S and Mizel A 2002 NSF nanoscale science and engineering grantees conference (Arlington, Virginia: National Science Foundation)

Riveros G, Green S, Cortes A, Gomez H, Marotti R E and Dalchiele E A 2006 Nanotechnology 17561

Routkevitch D, Bigioni T, Moskovits M and Xu J M 1996a J. Phys. Chem. 10014037

Routkevitch D, Tager A A, Haruyama J, Al Mawlawi D, Moskovits M and Xu M J 1996b IEEE Trans. Magn. 431646

Sauer G, Brehm G, Schneider S, Nielsch K, Wehrspohn R B, Choi J, Hofmeister H and Gösele U 2002 J. Appl. Phys. 91 3243

Schider G, Krenn J R, Gotschy W, Lamprecht B, Ditlbacher H, Leitner A and Aussenegg F R 2001 J. Appl. Phys. 903825

Schider G, Krenn J R, Hohenau A, Ditlbacher H, Leitner A and Aussenegg F R 2003 Phys. Rev. B68 155427 
Seadi A and Ghorbani M 2005 Mater. Chem. \& Phys. 91417

Sellmyer D J, Zheng M and Skomski R 2001 J. Phys. Condens. Matter 13 R433

Shimizu K, Kobayashi K, Thompson G E and Wood G C 1992 Philos. Mag. A66 643

Skomsk R, Zeng H and Sellmyer D J 2000 Phys. Rev. B62 3900

Spencer M J S, Hung A, Snook I K and Yarovsky I 2002 Surf. Sci. $\mathbf{5 1 3} 389$

Sugawara A, Coyle T, Hembree G G and Scheinfein M R 1997 Appl. Phys. Lett. 701043

Sun L, Searson P C and Chien C L 1999 Appl. Phys. Lett. 74 2803

Takahara J, Yamagishi S, Taki H, Morimoto A and Kobayashi T 1997 Opt. Lett. 22475

Terry T, Xu R, Piner D and Rodney S 2003 Langmuir 191443

Thompson G E and Wood G C 1983 Treatise on materials science and technology (New York: Academic Press) Vol. 23, pp 205-329

Thurn-Albrecht T et al 2000 Science 2902126

Tong L, Gattass R R, Ashcom J B, He S, Lou J, Shen M, Maxwell I and Mazur E 2003 Nature 42618

Tonucci R J, Justus B L, Campillo A J and Ford C E 1992 Science 258783

Uchi H, Kanno T and Alwitt R S 2001 J. Electrochem. Soc. 148 B17

van Vugt L K, Sandra J, Veen S J, Bakkers E P A M, Roest A L and Vanmaekelbergh D 2005 J. Am. Chem.. Soc. 12712357

van Wees B J, van Houten H, Beenakker C W J, Williamson J G, Kouvenhoven L P, van der Marel D and Foxon C T 1988 Phys. Rev. Lett. 60848

Venkatasubramanian R, Siivola E, Colpitts T and O'Quinn B 2001 Nature 413597

Vitos L, Ruban A V, Skriver H L and Kollár J 1998 Surf. Sci. 411186

Wanekaya A K, Chen W, Myung N V and Mulchandani A 2006 Electroanalysis 18533

Wang B, Yin S, Wang G and Zhao J 2001 J. Phys.: Condens. Matter 13 L403
Way Z L 2003 Nanowires and nanobelts materials preparation and devices, metal and semiconductor nanowires (Boston: Kluwer Academic Publication) Vol. 1

Wharam D A et al 1988 J. Phys. C: Solid State Phys. 21 L209

Whitney T W, Jiang J S, Searoon P C and Chien C L 1993 Science 2611316

Wu C G and Bein T 1994 Science 2641757

Wu Y and Yang P 2000 Chem. Mater. 12605

Wu Y, Fan R and Yang P 2002 Nano. Lett. 283

$\mathrm{Xu} \mathrm{D}, \mathrm{Xu} \mathrm{Y}$, Chen D, Guo G, Gui L and Tang Y $2000 A d v$. Mater. 12520

Xu D S, Chen D P, Xu Y J, Shi X S, Guo G L, Gui L L and Tang Y Q 2000 Pure Appl. Chem. 72127

Xu Y, Thompson G E and Wood G C 1985 Trans. Inst. Met. Finish. 6398

Yi G and Schwarzacher W 1999 Appl. Phys. Lett. 741746

Ying I Y 1999 Sci. Spectra 1856

Yu P Y and Cardona M 1995 Fundamentals of semiconductors (Berlin, Heidelberg: Springer) Ch. 7

Zelenski C M and Dorhout P K 1998 J. Am. Chem. Soc. 120 734

Zeng H, Zheng M, Skomski R, Sellmyer D J, Liu Y, Menon L and Bandyopadhyay S 2000 J. Appl. Phys. 874718

Zeng H, Skomki R, Menon L, Liu Y, Bandyopadhyay S and Sellmyer D J 2002 Phys. Rev. B65 13426

Zhang X Y, Zhang L D, Lei Y, Zhao L X and Mao Y Q $2001 \mathrm{~J}$. Mater. Chem. 111732

Zhang Z, Sun X, Dresselhaus M S, Ying J Y and Heremans J 1998a Appl. Phys. Lett. 731589

Zhang Z, Ying J Y and Dresselhaus M S 1998b J. Mater. Res. 131745

Zhang Z, Gekhtman D, Dresselhaus M S and Ying J Y 1999 Chem. Mater. 111659

Zhang Z, Sun X, Dresselhaus M S, Ying J Y and Heremans J 2000 Phys. Rev. B61 4850

Zheng M J, Zhang L D, Li G H and Chen W Z 2002 Chem. Phys. Lett. 363123

Zhao J, Buia C, Han J and Lu J P 2003 Nanotechnology 14501 